\title{
Insights into Equilibrium and Adsorption Rate of Phenol on Activated Carbon Pellets Derived from Cigarette Butts
}

\author{
Nahum A. Medellín-Castillo ${ }^{1,2}$, Raúl Ocampo-Pérez ${ }^{3, *}$, Angélica Forgionny ${ }^{4}$, Gladis J. Labrada-Delgado ${ }^{5}$, \\ Ana I. Zárate-Guzmán ${ }^{3}$ (D), Sergio A. Cruz-Briano ${ }^{2}$ and Rogelio Flores-Ramírez ${ }^{2}$ iD \\ 1 Facultad de Ingeniería, Universidad Autónoma de San Luis Potosí, Av. Manuel Nava No. 8, \\ San Luis Potosí 78290, Mexico; nahum.medellin@uaslp.mx \\ 2 Programa Multidisciplinario de Posgrado en Ciencias Ambientales, Universidad Autónoma de San Luis \\ Potosí, Av. Manuel Nava No. 201, San Luis Potosí 78210, Mexico; a176832@alumnos.uaslp.mx (S.A.C.-B.); \\ rogelio.flores@uaslp.mx (R.F.-R.) \\ 3 Centro de Investigación y Estudios de Posgrado, Facultad de Ciencias Químicas, Universidad Autónoma de \\ San Luis Potosí, San Luis Potosí 78260, Mexico; aizg_08@hotmail.com \\ 4 Grupo de Materiales con Impacto, Mat\&mpac, Facultad de Ciencias Básicas, Universidad de Medellín, \\ Medellín 55450, Colombia; mforgionny@udem.edu.co \\ 5 División de Materiales Avanzados, Instituto Potosino de Investigación Científica y Tecnológica A.C., \\ San Luis Potosí 78216, Mexico; gladis.labrada@ipicyt.edu.mx \\ * Correspondence: raul.ocampo@uaslp.mx
}

Citation: Medellín-Castillo, N.A.; Ocampo-Pérez, R.; Forgionny, A.;

Labrada-Delgado, G.J.;

Zárate-Guzmán, A.I.;

Cruz-Briano, S.A.; Flores-Ramírez, R. Insights into Equilibrium and Adsorption Rate of Phenol on Activated Carbon Pellets Derived from Cigarette Butts. Processes 2021, 9 , 934. https://doi.org/10.3390/ pr9060934

Academic Editor:

Monika Wawrzkiewicz

Received: 19 April 2021

Accepted: 24 May 2021

Published: 26 May 2021

Publisher's Note: MDPI stays neutral with regard to jurisdictional claims in published maps and institutional affiliations.

Copyright: (c) 2021 by the authors. Licensee MDPI, Basel, Switzerland. This article is an open access article distributed under the terms and conditions of the Creative Commons Attribution (CC BY) license (https:// creativecommons.org/licenses/by/ $4.0 /)$.
Abstract: In the present work, the preparation of activated carbon pellets from cigarette butts by thermal treatment was evaluated. The morphological, textural, topological, and surface chemical properties were studied by SEM-EDX, $\mathrm{N}_{2}$ adsorption, Raman, and FTIR spectroscopy. For adsorption assays, activated carbon was tested for the adsorption of phenol as a model molecule at different solution $\mathrm{pH}$, temperature, and type of water. In addition, leaching tests before and after carbonization were conducted to evaluate the lixiviation of ions present in the solid. The results revealed a microporous material, composed of cylindrical fibers (thickness of $13 \mu \mathrm{m}$ ) with a microporous area of $713 \mathrm{~m}^{2} / \mathrm{g}$ and narrow and uniform slit-shaped pores $(0.4-0.8 \mathrm{~nm})$. The surface chemistry analysis evidenced the presence of oxygenated groups (carboxylic, esters, and phenolics). Activated carbon leaching tests indicated that the concentrations of the leached ions did not exceed the maximum permissible limit for drinking water. Phenol adsorption revealed an exothermic process with a maximum adsorption capacity of $272 \mathrm{mg} / \mathrm{g}$ at $10{ }^{\circ} \mathrm{C}$. Finally, it was confirmed that phenol diffusion was drastically affected by hindered phenomena due to the similarity in the molecular size of phenol and the average size of micropores, and as a result an effective diffusion coefficient between $6.10 \times 10^{-0}$ and $5.50 \times 10^{-12} \mathrm{~cm}^{2} / \mathrm{s}$ and a maximum tortuosity value of 3.3 were obtained.

Keywords: cigarette butts; filter; activated carbon; adsorption; phenol

\section{Introduction}

At present, there are several environmental concerns related to waste generation derived from different anthropogenic activities [1]. One of the main issues in waste management is the treatment and disposal of cigarette butts (CBs), given that their toxic characteristics represent a risk to human health and environment. Previous reports showed that CBs have more than 4000 toxic chemical compounds, including nicotine, nicotine alkaloids, compounds specific to solanaceae, catechols, aromatic hydrocarbons, and polycyclic aromatic hydrocarbon (PAH), and these represent hazardous risks for living organisms and their environment [1,2]. The main components of CBs are a filter (generally made of cellulose acetate), tobacco residues, paper, and ashes [3]. In addition, CBs are considered one of the most abundant municipal waste materials [4]. The estimated amount of global discarded cigarette waste is about $340-680$ million $\mathrm{kg}$ by year [1]. Furthermore, it was projected that smokers would consume approximately nine trillion cigarettes worldwide by 
2025 [3]. The most common alternatives for the management of CB wastes are incineration and landfilling; however, the emission of toxic compounds and the leaching of heavy metals can occur in the environment [5]. In this regard, different recycling methods and practices have been proposed to allow for the valorization of CB waste, such as mixing in construction materials, cellulose pulp production, corrosion inhibition, and preparation of carbonaceous materials, among others [2]. These valorization methods are effective and environmentally friendly alternatives to reduce the impact of CB waste $[2,6]$. Of this group of technologies, the development of carbonaceous materials stands out due to the fact that it be considered an economical and efficient alternative, since developing of commercial activated carbons implies a high-cost complex manufacturing process [7]. In this sense, $C B$ waste transformation into activated carbons pellets is an alternative for obtaining low-cost adsorbents and for solving environmental problems, such as the presence of toxic pollutants in water and wastewater. Lima et al. [8] prepared activated carbon from CBs through a hydrothermal carbonization process with $\mathrm{NaOH}$ activation $\left(\mathrm{S}_{\mathrm{BET}} 3.74 \mathrm{~m}^{2} \mathrm{~g}^{-1}\right.$, irregular morphology) and successfully tested for the adsorption of methylene blue, achieving a maximum adsorption capacity of $532.9 \mathrm{mg} \mathrm{g}^{-1}$. On the other hand, Alhokbany et al. [4] obtained a highly porous functionalized carbon material from CBs prepared by means of a carbonization and hydrothermal process, and they studied the adsorption process of bisphenol; they found that the process is endothermic and spontaneous in nature, and that the adsorption mechanism was due to electrostatic and $\pi-\pi$ interactions, achieving a bisphenol A removal efficiency of 92.47\%. Finally, Manfrin et al. [9] and Conradi et al. [7] evaluated the adsorption of lead on activated carbon derived from $\mathrm{CBs}$ with a different chemical activation process $\left(\mathrm{NaOH}, \mathrm{ZnCl}_{2}\right.$ and $\left.\mathrm{ZnCl}_{2}+\mathrm{CO}_{2}\right)$; the materials presented a tubular structure and spongy aspects with broad surface functional groups (alkane, aldehyde, hydroxyl, carboxylic acid, carbonate, alcohol, and ether). The studies revealed that the adsorption process between adsorbate and adsorbent was due to chemical interactions between oxygenated groups and $\mathrm{Pb}^{2+}$. The maximum adsorption capacities obtained were in the order of 17.9 and $84.7 \mathrm{mg} \mathrm{g}^{-1}$. Although the studies reported above represent an important contribution, it is necessary to describe the mass transfer mechanisms that govern the adsorption process in order to fully understand the phenomenon and establish the optimal conditions for the operation of the adsorption system.

The present work aims to prepare activated carbon pellets with CBs as raw material using a simple thermal method that allows the original monolithic structure of the precursor to be maintained, which is not a common characteristic accomplished in previous studies using CBs [4,7-9]. The efficiency of the activated carbon is evaluated by investigating the equilibrium and adsorption rate of phenol in aqueous solution. In addition, a deeper comprehension of the mass transfer mechanism governing the overall adsorption rate is attempted by applying diffusional models. Finally, leaching tests before and after carbonization demonstrate the advantages of this process in minimizing the release of secondary contaminants into the environment. In this study, the phenol molecule is used as a model pollutant, based on the consideration that it is a toxic organic pollutant that is widely found in industrial wastewater, its degradation is difficult, and it is reported to produce harmful effects on human health by inhalation and skin contact [10,11].

\section{Materials and Methods}

\subsection{Materials}

CBs of different trademarks were collected at the campus of the Autonomous University of San Luis Potosi, in San Luis Potosi, Mexico. CBs that presented defects on their cylindrical structure were discarded. As a first step, the unburned cigarette body of the cigarette was removed, and then the outer wrapping paper was stripped. Subsequently, the CBs were placed in an oven at $90{ }^{\circ} \mathrm{C}$ overnight to remove the excess of moisture. Finally, the dried CBs were placed in a sealed container for further processing. 


\subsection{Preparation of Hierarchical Activated Carbon}

According to the thermogravimetric (TGA) and differential scanning calorimetry (DSC) analyses (see Figures S1 and S2 in Supplementary Materials), cellulose acetate fibers were thermally stable at temperatures below $200{ }^{\circ} \mathrm{C}$. Two steps were observed in the TGA analysis. A weight loss around $115^{\circ} \mathrm{C}$ was due to dehydration of the material (15 wt.\%), while a significant second weight loss that was observed from 200 to $600{ }^{\circ} \mathrm{C}$ was associated with the decomposition of the lignocellulosic material (75 wt.\%) [12]. A residue of $10 \mathrm{wt} . \%$ was obtained. From the DSC analysis, an exothermic melting process occurred at temperatures close to $300{ }^{\circ} \mathrm{C}$ where $90 \%$ of the initial mass was lost. Based on this information and to avoid losing the main structure exhibited by the CBs, the following procedure was performed to obtain activated carbon. A mass of $10 \mathrm{~g}$ of CBs was loaded in a crucible and placed in a furnace tube (Carbolite Gero model CTF 12/65/550, England) for carbonization at $200{ }^{\circ} \mathrm{C}$ for $2 \mathrm{~h}\left(1{ }^{\circ} \mathrm{C} \mathrm{min}-1\right)$ under $\mathrm{N}_{2}$ flow of $100 \mathrm{~mL} \mathrm{~min}{ }^{-1}$. The heating rate of $1{ }^{\circ} \mathrm{C} \mathrm{min}-1$ was chosen because higher values produce the melting of the fibers, resulting in the loss of the morphology. Subsequently, the furnace was turned off, and the $\mathrm{N}_{2}$ stream was replaced by an air stream $\left(100 \mathrm{~mL} \mathrm{~min}^{-1}\right)$ until room temperature was reached. This step was performed to incorporate oxygen functional groups to stabilize the carbon fibers. Afterwards, the sample was treated in a two-step thermal program under $\mathrm{N}_{2}$ flow $\left(100 \mathrm{~mL} \mathrm{~min}^{-1}\right)$, which was performed firstly at $300^{\circ} \mathrm{C}$ for $2 \mathrm{~h}\left(5^{\circ} \mathrm{C} \mathrm{min}-1\right)$ and then the temperature was raised to $550{ }^{\circ} \mathrm{C}$ for $1 \mathrm{~h}\left(10^{\circ} \mathrm{C} \mathrm{min}^{-1}\right)$. Finally, the sample was physically activated under $\mathrm{CO}_{2}$ atmosphere at $850{ }^{\circ} \mathrm{C}$ for $2 \mathrm{~h}$ through a flow of $100 \mathrm{~mL} \mathrm{~min}^{-1}$ at a heating rate of $10{ }^{\circ} \mathrm{C} \mathrm{min}^{-1}$.

\subsection{Chemical and Textural Characterization}

Textural properties of the activated carbon were determined by $\mathrm{N}_{2}$ adsorption-desorption isotherms at $-196{ }^{\circ} \mathrm{C}$ using a Micromeritics ASAP 2020 analyzer (Micromeritics Instrument Corporation, USA). Before measurements, the sample was degassed at $100^{\circ} \mathrm{C}$ under vacuum (pressure $\approx 10^{-2} \mathrm{~Pa}$ ) for $12 \mathrm{~h}$ as previously reported by other authors [13,14]. The pore volume was determined at $\mathrm{P} / \mathrm{P}_{0} \approx 0.98$, and the micropore volume $\left(\mathrm{W}_{0}\right)$ was obtained by applying the Dubinin-Radushkevich method. On the other hand, the Stoeckli equation [15] was applied to estimate the surface area and the average micropore width $\left(\mathrm{L}_{0}\right)$. In addition, the pore size distribution of the sample was characterized by using nonlocal density functional theory methods (NLDFT) [16]. The surface and morphology of the particles were observed in an ESEM, i.e., model Quanta 250, FEI, Brno, Czech Republic. To show the distribution of chemical elements on the surface, an energy dispersive spectroscopy (EDS) elemental mapping was performed using an EDAX microprobe, model Octane Plus, NJ, USA.

The functional groups of CBs and activated carbon were identified by means of an FTIR spectrophotometer (Thermo Scientific, model Nicolet iS10, WI, USA). Infrared spectra were collected over a spectral range of 500 to $4000 \mathrm{~cm}^{-1}$. The activated carbon samples were prepared in mixture with $\mathrm{KBr}$ in a ratio of 1:500.

The concentration of active sites of activated carbon was determined based on the method proposed by Boehm (1994) [17]. Additionally, the $\mathrm{pH}$ of zero charge point ( $\mathrm{pH}_{\mathrm{PZC}}$ ) was determined by a titration method preparing various $0.01 \mathrm{~N} \mathrm{NaCl}$ solutions with $0.004 \mathrm{~N} \mathrm{NaOH}$ and $0.1 \mathrm{~g}$ of activated carbon. After $48 \mathrm{~h}$, the solution $\mathrm{pH}$ was recorded, and the solution was titrated with a $0.1 \mathrm{~N} \mathrm{HCl}$ solution. In addition, solutions were prepared without activated carbon. The $\mathrm{pH}_{\mathrm{PZC}}$ was determined with the solution $\mathrm{pH}$ at which the titration curve with activated carbon intersects the titration curve without an adsorbent.

Finally, in order to study the topological structure of the activated carbon, Raman spectra were recorded using a RENISHAW InVía MicroRaman (Wotton-under-Edge, UK) with $532 \mathrm{~nm}$ laser operating at ca. $0.4 \mathrm{~mW}(1 \%)$ and 1800 lines per mm grating. Spectra were collected by averaging 5 acquisitions of $60 \mathrm{~s}$ duration. The Raman shift was calibrated using the Rayleigh peak and the $520.7 \mathrm{~cm}^{-1}$. 


\subsection{CBs and Activated Carbon Leaching Test}

The leaching of CBs and activated carbon in aqueous systems was evaluated by determining the content of heavy metals and other parameters for drinking water in $1 \mathrm{~L}$ of deionized water. The CBs were placed in a $15 \mathrm{~cm}^{3}$ acrylic column, and $1 \mathrm{~L}$ of water was recirculated using a peristaltic pump with a volumetric flow of $5 \mathrm{~cm}^{3} \mathrm{~min}^{-1}$ for $48 \mathrm{~h}$. The same process was performed with the activated carbon. The resulting solution was analyzed by inductively coupled plasma optical emission spectrometry (ICPOES) using a Varian 738 ES (Springvale, Australia) and according to the parameters established by the Mexican legislation and the values suggested by the WHO. Moreover, a gas chromatography analysis was performed to identify the main organic substances. This analysis was carried out by a direct injection of $1 \mu \mathrm{L}$ of the sample into a gas chromatograph (Agilent 6890) equipped with a $30 \mathrm{~m}$ long, $0.25 \mathrm{~mm}$ internal diameter $\mathrm{HP}-5 \mathrm{M}(95 \%)$ polydimethylsiloxane $(95 \%)$ capillary column. An initial temperature of $90^{\circ} \mathrm{C}$ was used, which remained constant for $2 \mathrm{~min}$, and then heated at a rate of $10^{\circ} \mathrm{C} \mathrm{min}-1$ to a final temperature of $230{ }^{\circ} \mathrm{C}$. The temperature of the interface was maintained at $280^{\circ} \mathrm{C}$. The following conditions were used in the mass detector: temperature of the ionization chamber at $230{ }^{\circ} \mathrm{C}$, helium as a carrier gas, and a flow rate of $0.9 \mathrm{~mL} \mathrm{~min}^{-1}$.

\subsection{Adsorbate}

Phenol with a purity $>99.9 \%$ was used as an adsorbate model molecule. Its physicochemical properties are presented in Table 1 . The concentration of phenol in the aqueous solution was determined by UV-Vis spectroscopy. The absorbance of the phenol sample was determined using a double-beam spectrophotometer (Shimadzu, UV-160, Kyoto, Japan) at a wavelength of $269 \mathrm{~nm}$.

Table 1. Physicochemical properties of phenol, adapted with permission from [18].

\begin{tabular}{|c|c|c|c|c|c|c|}
\hline Compound & $\begin{array}{l}\text { Molecular } \\
\text { Structure }\end{array}$ & $\begin{array}{l}\text { Molecular } \\
\text { Formula }\end{array}$ & $\mathrm{pK}_{\mathrm{a}}$ & ${ }^{*} \mathrm{D}_{\mathrm{AB}} \times 10^{6} \mathrm{~cm}^{2} \mathrm{~s}^{-1}$ & Molecular Weight ( $\mathrm{g} \mathrm{mol}^{-1}$ ) & Size $X, Y(n m)$ \\
\hline Phenol & & $\mathrm{C}_{6} \mathrm{H}_{6} \mathrm{O}$ & 9.86 & 8.1 & 94.11 & $\begin{array}{l}0.43 \\
0.57\end{array}$ \\
\hline
\end{tabular}

* Experimental molecular diffusivity of phenol in water at $\mathrm{T}=25^{\circ} \mathrm{C}$, taken with permission from [19].

\subsection{Equilibrium Experiments}

Adsorption equilibrium experiments were carried out in a batch system using $50 \mathrm{~mL}$ plastic centrifuge tubes (adsorbers). For experiments, a specific mass of the activated carbon $(0.1 \mathrm{~g})$ was added together with phenol solutions $(40 \mathrm{~mL})$ of a known initial concentration (10 to $2000 \mathrm{mg} \mathrm{L}^{-1}$ ). Deionized water with a conductivity $<<0.055 \mu \mathrm{S} \mathrm{cm}{ }^{-1}$ was used to prepare all solutions. The adsorbent-solution mix was left in contact until reaching equilibrium (21 days) under shaking, and the temperature was controlled by immersing the adsorbers in a constant-temperature bath. The effect of the solution $\mathrm{pH}$ was analyzed at values of 2, 5, 7, 10, and 11, using phenol solutions with a concentration of $500 \mathrm{mg} \mathrm{L}^{-1}$. The solution $\mathrm{pH}$ was kept constant by adding drops of $0.01 \mathrm{~N} \mathrm{NaOH}$ or $0.1 \mathrm{~N} \mathrm{HCl}$. After reaching equilibrium, the final phenol concentration was determined, and the mass of phenol adsorbed at equilibrium was calculated using the following equation:

$$
\mathrm{q}_{\mathrm{e}}=\frac{\mathrm{V}\left(\mathrm{C}_{\mathrm{A} 0}-\mathrm{C}_{\mathrm{e}}\right)}{\mathrm{m}}
$$

where $\mathrm{q}_{\mathrm{e}}$ is the mass of phenol adsorbed $\left(\mathrm{mg} \mathrm{g}^{-1}\right), \mathrm{V}$ corresponds to the volume of the solution $(\mathrm{L}), \mathrm{m}$ is the mass of the adsorbent $(\mathrm{g}), \mathrm{C}_{\mathrm{A} 0}$ represents the initial concentration $\left(\mathrm{mg} \mathrm{L}^{-1}\right)$, and $\mathrm{C}_{\mathrm{e}}$ denotes the equilibrium concentration $\left(\mathrm{mg} \mathrm{L}^{-1}\right)$. The adsorption equilib- 
rium data of phenol from wastewater were obtained by preparing solutions of phenol using wastewater that exited a treatment plant located in San Luis Potosi, Mexico. The physicochemical characteristics of the wastewater were determined by the standard examination methods and are reported in Table S1 in the Supplementary Materials.

\subsection{Obtaining the Concentration Decay Curves}

The concentration decay curves of phenol on activated carbon were obtained using a rotating basket batch system that consisted of a three-necked reaction flask with two stainless steel mesh baskets coupled to a metal tube actuated for a variable-speed motor. The mechanical details of the rotating system can be found in a previous publication [20]. The adsorbent $(1 \mathrm{~g})$ was placed inside the two baskets, and $1 \mathrm{~L}$ of a phenol solution at pH 7 (concentration from 100 to $1500 \mathrm{mg} \mathrm{L}^{-1}$ ) was added to the reactor. The system was stirred at $200 \mathrm{rpm}$. Previous studies reported that stirring speeds higher than $200 \mathrm{rpm}$ do not affect the adsorption rate. The temperature was controlled through partial immersion of the reactor in a constant-temperature bath. The phenol concentration over time was monitored, sampling aliquots of $1 \mathrm{~mL}$ of the solution until the equilibrium condition; the total subtracted volume did not exceed $5 \%$ of the total volume, and so the total volume was assumed constant. The phenol concentration decay curve was constructed by plotting the dimensionless concentration $\left(\mathrm{C}_{\mathbf{A}} / \mathrm{C}_{\mathbf{A 0}}\right)$ against time $(\mathrm{t})$.

\section{Results}

\subsection{Characterization of CBs and Activated Carbon Pellets}

The morphology of CBs before the carbonization process is presented in Figure 1a-c. Raw material consisted of a set of Y-shape cellulose acetate fibers interwoven in an axial direction with an average thickness of $25 \mu \mathrm{m}$. After the carbonization process, the filter volume was drastically reduced up to 35 folds but its monolithic shape was maintained as illustrated in Figure 1d,g,h, indicating that the heating program to produce the activated carbon was optimal. The conservation of a monolithic shape is not a common characteristic, as found in previous studies using CBs $[4,7,9,10]$. In this sense, other experiments show that an increase in the heating rate or operation temperatures produced a complete melting of the fibers. On the other hand, the fibers suffered a visible morphological change (see Figure 1e,f), as it switched from a Y-type fiber to a cylindrical fiber with an average diameter of $13 \mu \mathrm{m}$. This transition can be due to the polymerization of the cellulose chains to a more stable configuration due to the high calcination temperature. Finally, the overall yield for the activated carbon production was $11 \%$ due to the weight of the filters used as raw material.

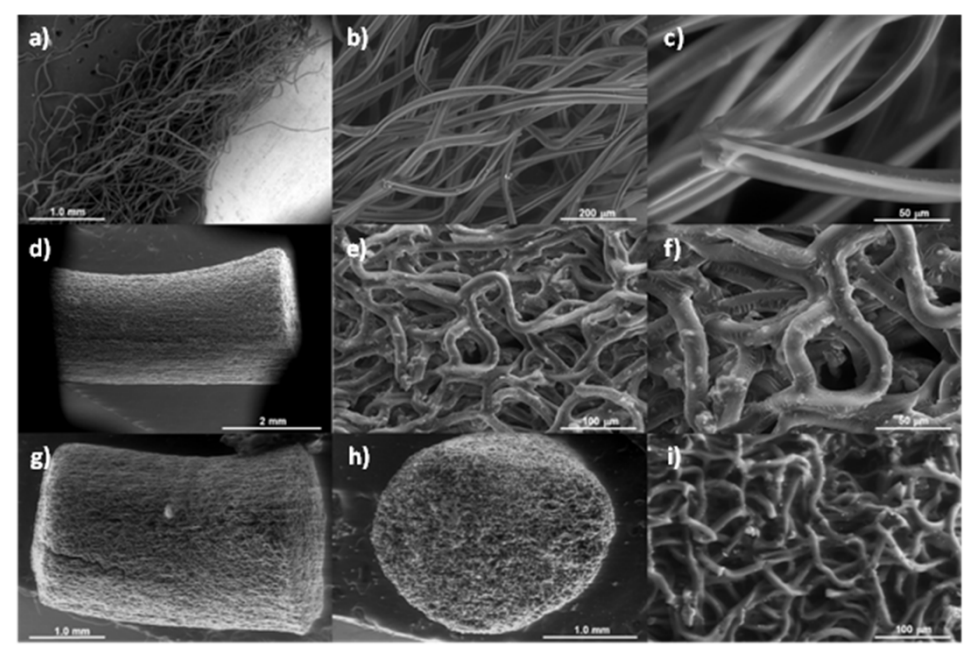

Figure 1. Micrographs obtained by SEM for raw material $(\mathbf{a}-\mathbf{c})$ and activated carbon $(\mathbf{d}-\mathbf{i})$. 
The EDS elemental mapping performed on the surface of the activated carbon is displayed in Figure 2. These results allowed for the identification of C, K, Ti, O, Al, Si, Ca, and $\mathrm{Fe}$, with $\mathrm{K}$ and $\mathrm{Ti}$ standing out, since these can be derived from the additives added to tobacco, where $\mathrm{K}$ is added as potassium sorbate and $\mathrm{Ti}$ as titanium dioxide [21]. Moreover, it is notable that elemental carbon is the main chemical element in activated carbon with $89.5 \mathrm{wt}$.\% while in the case of oxygen at about $8.5 \mathrm{wt} . \%$ and for the other constituents at 2 wt.\%.

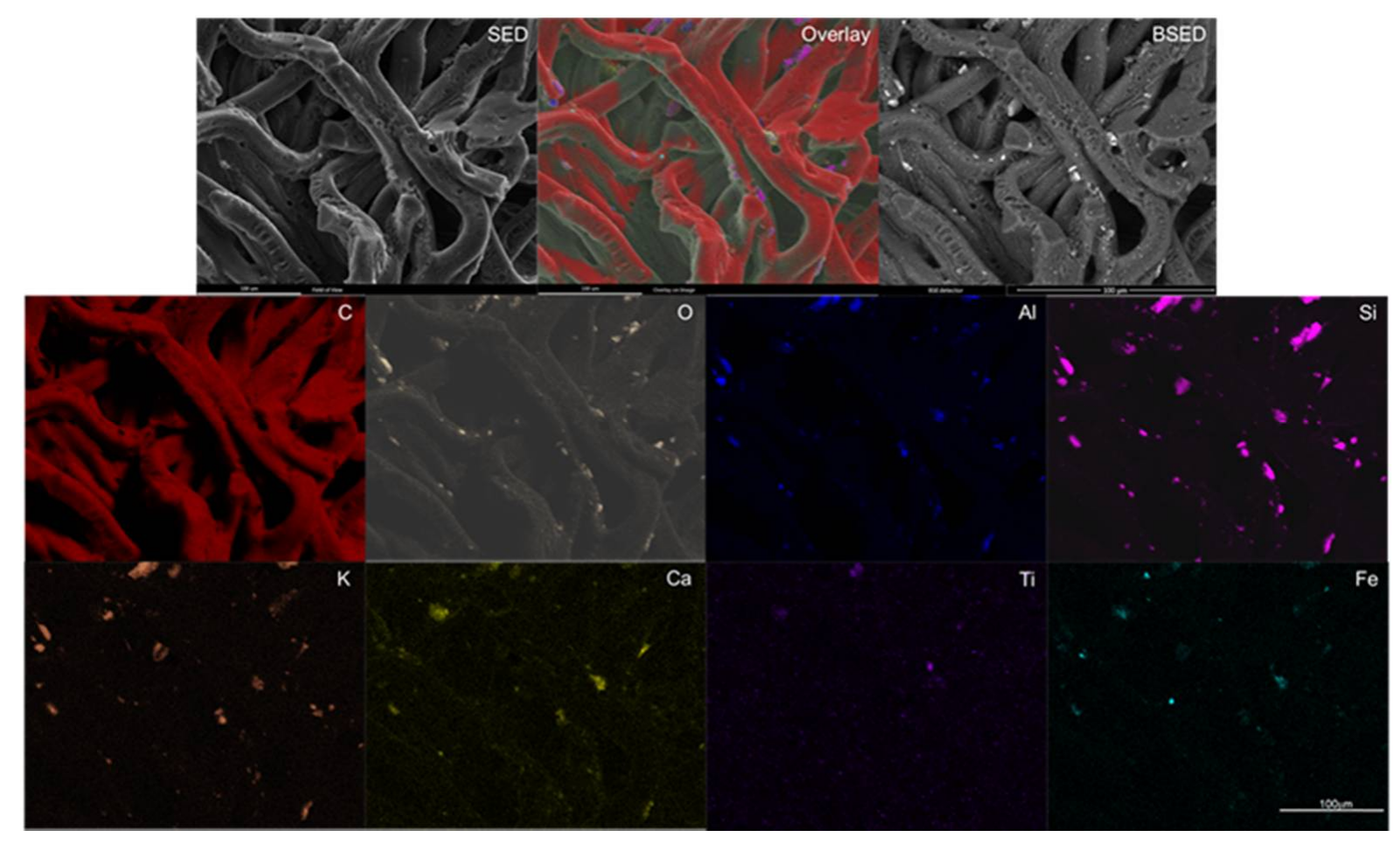

Figure 2. EDS mapping of $\mathrm{C}, \mathrm{O}, \mathrm{Al}, \mathrm{Si}, \mathrm{K}, \mathrm{Ca}, \mathrm{Ti}$, and $\mathrm{Fe}$ at the surface of the activated carbon.

Figure 3 depicts the $\mathrm{N}_{2}$ adsorption isotherm for the activated carbon prepared by activation with $\mathrm{CO}_{2}$. The isotherm presented a step shape with a high amount of $\mathrm{N}_{2}$ adsorbed at low pressures $\left(\mathrm{V}_{\text {liq }}=0.20 \mathrm{~cm}^{3} \mathrm{~g}^{-1}\right)$, indicating a strong interaction between the $\mathrm{N}_{2}$ molecules and the surface of the material. Moreover, an increase in the relative pressure slightly raised the amount of $\mathrm{N}_{2}$ adsorbed by obtaining a value of $0.253 \mathrm{~cm}^{3} \mathrm{~g}^{-1}$ at $\mathrm{P} / \mathrm{P}_{0}=0.98$. According to the International Union of Pure and Applied Chemistry, the adsorption isotherm showed a type $1 \mathrm{~A}$ behavior, which is characteristic of microporous materials composed with narrow and uniform slit-shaped pores [22]. From the application of the Dubinin-Radushkevich method, the estimated microporous area was $\mathrm{S}_{\text {mic }}=713 \mathrm{~m}^{2} \mathrm{~g}^{-1}$ with a micropore volume of $W_{0}=0.22 \mathrm{~cm}^{3} \mathrm{~g}^{-1}$, indicating that $87 \%$ of the total porous structure corresponds to micropores. The obtained microporous area was higher than the reported values in the literature for the activated carbons prepared from lignocellulosic waste that used $\mathrm{ZnCl}_{2}$ as an activating agent [23]. The pore size distribution obtained from the application of the NLDFT method is also observed in Figure 3. An unimodal distribution of narrow pores between 0.4 and $0.8 \mathrm{~nm}$ with a slight presence of wide micropores was determined. Moreover, an average micropore width of $\mathrm{L}_{0}=0.62 \mathrm{~nm}$ was obtained. These results suggest that despite the excellent material-specific area, its application as an adsorbent must be addressed to low-sized molecules (less than $8 \mathrm{~nm}$ ) to promote diffusion into the narrow micropores. 


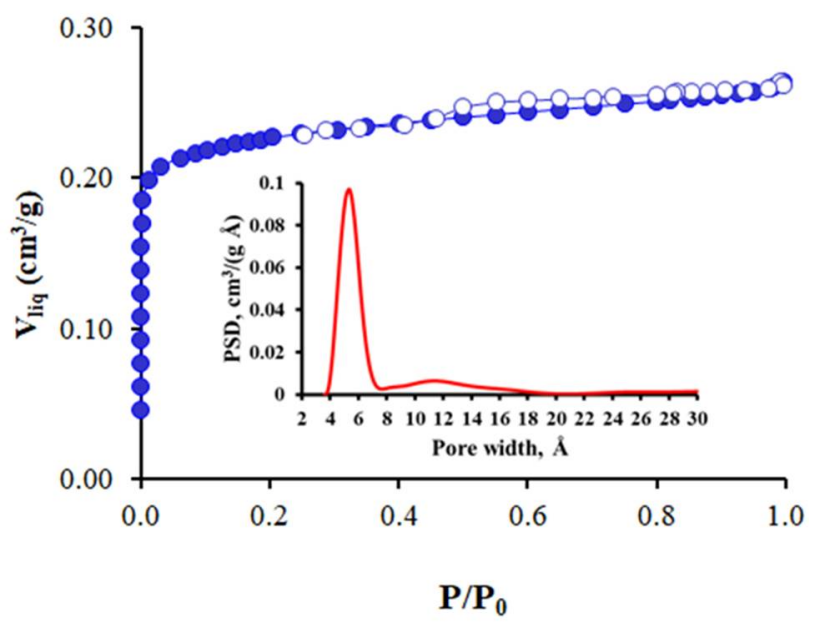

Figure 3. Adsorption isotherm of $\mathrm{N}_{2}$ at $77 \mathrm{~K}$ and pore size distribution obtained by NLDFT.

The FTIR spectra of CBs and activated carbon are shown in Figure S3 in the Supplementary Materials. The CBs spectrum has a band around $3400 \mathrm{~cm}^{-1}$, which is attributable to the $\mathrm{O}-\mathrm{H}$ stretching vibration of hydroxyl groups in cellulose and to the moisture in the material $[9,24]$. The bands observed from 3000 to $2850 \mathrm{~cm}^{-1}$ are attributed to the $\mathrm{sp}^{2}$ and $\mathrm{sp}^{3} \mathrm{C}-\mathrm{H}$ stretching vibration in aliphatic structures [24-26]. Bands associated with carbonyl groups $(-\mathrm{C}=\mathrm{O})$ and its hydroxyl $(-\mathrm{OH})$ deformation vibration were observed at $\approx 1720 \mathrm{~cm}^{-1}$ and $1640 \mathrm{~cm}^{-1}$, respectively [27]. The bands at $1430 \mathrm{~cm}^{-1}$ and $1320 \mathrm{~cm}^{-1}$ are relative to the $\mathrm{C}-\mathrm{H}$ stretching of $-\mathrm{CH}_{2}$ and $-\mathrm{CH}_{3}$ groups, confirming the presence of cellulose [24]. In addition, at $1200 \mathrm{~cm}^{-1}$, the band associated with C-O stretching of acetyl groups was observed, and at $1100 \mathrm{~cm}^{-1}$, the band is attributed to C-O stretching of hydroxyl in cellulose was observed [24]. After activation, some similar bands were observed in the FTIR spectrum of the activated carbon, with a decrease in their intensity. This was due to the cellulose content of the cigarette filters diminishing because the aromaticity of the material increased during the thermal treatment [7]. Thus, the presence of carboxylic or phenolic groups can be evidenced with a band at $3310 \mathrm{~cm}^{-1}$ related to $-\mathrm{O}-\mathrm{H}$ stretching, and the presence of the band at $1450 \mathrm{~cm}^{-1}$ could be associated with a complex arrangement of aromatic skeletal stretching vibration $(C=C$ vibration) $[28,29]$. The band at around $1200 \mathrm{~cm}^{-1}$ could be associated with the $\mathrm{C}-\mathrm{O}$ stretching vibration in esters, carboxylic groups, or phenolic groups [12].

The concentrations of the acidic and basic sites obtained by Bohem's method were 0.052 and 0.492 meq g $^{-1}$, respectively. Thus, the surface of the activated carbon was basic, and this result is confirmed by the fact that the value of $\mathrm{pH}_{\mathrm{PZC}}$ was 9.02. Finally, Figure 4 show the Raman spectra obtained for activated carbon, as seen in two well-defined peaks observed at $1336 \mathrm{~cm}^{-1}$ and $1585 \mathrm{~cm}^{-1}$, which can be assigned to defective band (D band) and graphitic band ( $G$ band), respectively. Moreover, the large estimated $I_{D} / I_{G}$ value (0.92) confirms the rich structure nature of the material, similarly to that reported for other hierarchically ordered carbon materials.

\subsection{Leaching Tests}

The results of the CBs and activated carbon leaching tests are presented in Tables 2 and 3. For the elements determined by the ICP-OES (Table 2), it could be observed that when CBs or activated carbon were placed in contact with deionized water, there was an increase in the concentration of all the elements in comparison to them being placed the deionized water, with the increase in concentration of CBs being more noticeable. Moreover, possible variations in the concentration may be attributed to the uncertainty of the method of analysis $<10 \%$ or to variations in the element concentrations of the deionized water used in the leaching tests or to the constituents of the chemicals used in the digestion 
of the test samples. However, results suggest that the concentrations and types of elements determined are not significant enough to produce possible effects on human health.

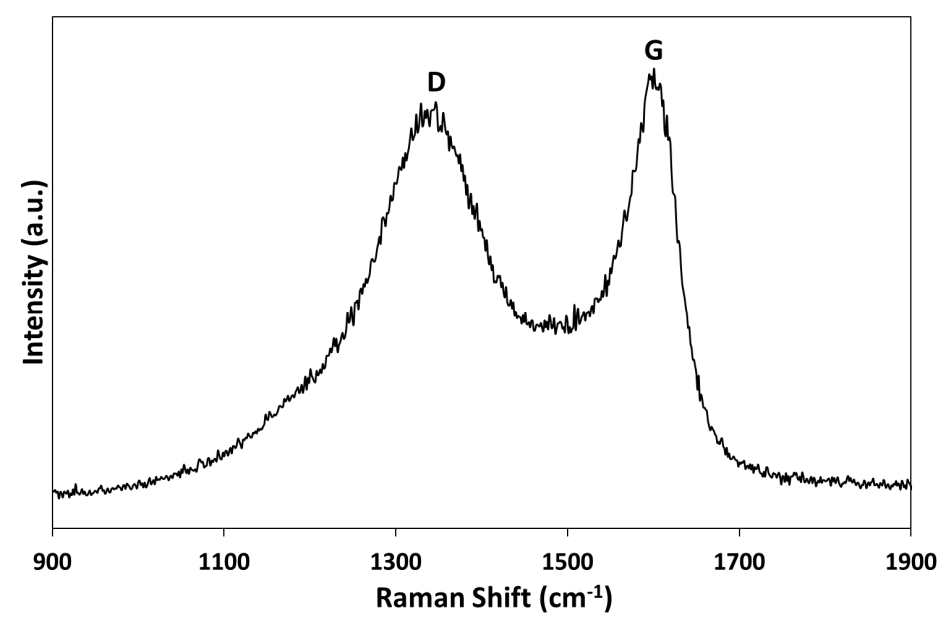

Figure 4. Raman spectra of activated carbon prepared from CBs.

Table 2. Elements determined by ICP-OES in leaching tests.

\begin{tabular}{|c|c|c|c|}
\hline Element & $\begin{array}{l}\text { Deionized Water } \\
\quad\left(\mathrm{mg} \mathrm{L}^{-1}\right)\end{array}$ & $\begin{array}{c}\text { Cigarette Butt } \\
\text { Leaching }\left(\mathrm{mg} \mathrm{L}^{-1}\right)\end{array}$ & $\begin{array}{l}\text { Activated Carbon } \\
\text { Leaching }\left(\mathrm{mg} \mathrm{L}^{-1}\right)\end{array}$ \\
\hline $\mathrm{Ag}$ & ND & $<0.003$ & ND \\
\hline $\mathrm{Al}$ & ND & 0.121 & ND \\
\hline As & ND & $<0.010$ & ND \\
\hline B & $<0.05$ & $<0.010$ & $<0.05$ \\
\hline $\mathrm{Ba}$ & 3.153 * & $<0.010$ & 5.900 * \\
\hline $\mathrm{Be}$ & ND & $<0.010$ & ND \\
\hline $\mathrm{Ca}$ & $<0.05$ & 0.842 & 2.139 \\
\hline $\mathrm{Cd}$ & ND & $<0.010$ & ND \\
\hline $\mathrm{Co}$ & ND & 0.023 & ND \\
\hline $\mathrm{Cr}$ & ND & $<0.010$ & ND \\
\hline $\mathrm{Cu}$ & ND & 0.062 & ND \\
\hline $\mathrm{Fe}$ & ND & $<0.010$ & ND \\
\hline $\mathrm{K}$ & 0.147 & 3.199 & 0.667 \\
\hline $\mathrm{Li}$ & 3.929 * & 0.569 & 6.340 * \\
\hline $\mathrm{Mg}$ & $<0.05$ & 0.218 & 0.101 \\
\hline $\mathrm{Mn}$ & 0.830 * & $<0.010$ & 3.233 * \\
\hline Mo & ND & $<0.010$ & ND \\
\hline $\mathrm{Na}$ & $<0.05$ & 0.849 & 0.082 \\
\hline $\mathrm{Ni}$ & ND & $<0.010$ & ND \\
\hline $\mathrm{P}$ & ND & $<0.010$ & ND \\
\hline $\mathrm{Pb}$ & ND & $<0.010$ & ND \\
\hline $\mathrm{Sb}$ & ND & $<0.010$ & ND \\
\hline Se & ND & $<0.010$ & ND \\
\hline $\mathrm{Si}$ & $<0.25$ & $<0.010$ & $<0.25$ \\
\hline Sn & ND & $<0.010$ & ND \\
\hline $\mathrm{Sr}$ & $1.353 *$ & $<0.010$ & $5.526^{*}$ \\
\hline $\mathrm{Ti}$ & ND & $<0.010$ & ND \\
\hline $\mathrm{Tl}$ & ND & $<0.010$ & ND \\
\hline $\mathrm{V}$ & ND & 0.137 & ND \\
\hline $\mathrm{Zn}$ & ND & $<0.010$ & ND \\
\hline
\end{tabular}

ND, not detectable; * $\mu \mathrm{g} \mathrm{L}^{-1}$. 
Table 3. Parameters of water for human consumption determined in the solution of leaching tests.

\begin{tabular}{|c|c|c|c|c|}
\hline \multirow{2}{*}{ Parameter } & \multirow{2}{*}{ CBs Leaching } & \multirow{2}{*}{ Activated Carbon Leaching } & \multicolumn{2}{|c|}{ Permissible Limits } \\
\hline & & & NOM & WHO \\
\hline $\mathrm{pH}$ & 5.12 & 7.8 & $6.5-8.5$ & NVP \\
\hline Color $(\mathrm{Co} / \mathrm{Pt})$ & 55.0 & Colorless & 20.0 & Colorless \\
\hline Odor & Tabaco & Odorless & Odorless & Odorless \\
\hline Turbidity (NTU) & 1.0 & 0.2 & 10.0 & $<0.2$ \\
\hline Total hardness $\left(\mathrm{mg} \mathrm{CaCO}_{3} \mathrm{~L}^{-1}\right)$ & 2.0 & 2.0 & 500 & NVP \\
\hline Ca hardness $\left(\mathrm{mg} \mathrm{CaCO}_{3} \mathrm{~L}^{-1}\right)$ & 2.0 & 2.0 & NVP & NVP \\
\hline $\mathrm{Mg}$ hardness $\left(\mathrm{mg} \mathrm{CaCO}_{3} \mathrm{~L}^{-1}\right)$ & 0.0 & 0.0 & NVP & NVP \\
\hline Chlorides $\left(\mathrm{mg} \mathrm{L}^{-1}\right)$ & 4.0 & 2.0 & 250 & NVP \\
\hline Fluorides $\left(\mathrm{mg} \mathrm{L}^{-1}\right)$ & 0.12 & 0.10 & 1.50 & 1.50 \\
\hline Nitrites $\left(\mathrm{mg} \mathrm{L}^{-1}\right)$ & Absent & Absent & 1.00 & 3.00 \\
\hline Nitrates $\left(\mathrm{mg} \mathrm{L}^{-1}\right)$ & 0.11 & 0.15 & 10.0 & 50.0 \\
\hline Sulfates $\left(\mathrm{mg} \mathrm{L}^{-1}\right)$ & 4.50 & 4.00 & 400 & NVP \\
\hline $\begin{array}{c}\text { Mesophilic Aerobic } \\
\text { Microorganisms (UFC } \mathrm{mL}^{-1} \text { ) }\end{array}$ & Absent & Absent & NVP & NVP \\
\hline Total coliforms (NMP/100 mL) & Absent & - & Absent & Absent \\
\hline Fecal coliforms (NMP/100 mL) & Absent & - & Absent & Absent \\
\hline Total dissolved solids $\left(\mathrm{mg} \mathrm{L}^{-1}\right)$ & 10.5 & - & 1000 & NVP \\
\hline Chlorine (mg L $\left.{ }^{-1}\right)$ & Absent & - & $0.10-0.50$ & 5.00 \\
\hline
\end{tabular}

Table 3 shows the parameters determined for the water generated in the leaching tests and the maximum permissible limit for each parameter measured according to the Mexican Official Standards (NOM) [30] and the World Health Organization Guidelines for Drinking Water Quality (WHO, 2017) [31]. Leaching tests for CBs show leaching with an acidic $\mathrm{pH}$ and a $55.0 \mathrm{Co} / \mathrm{Pt}$ color; moreover, a characteristic odor was produced, which caused the water to not comply with both Mexican legislation and what was suggested by the WHO. In the case of activated carbon, it can be observed that no concentration was above the maximum permissible limit in water for human consumption. Thus, it was demonstrated that the activated carbon prepared from CBs could be used to treat water for human consumption.

Gas chromatography (GC) analyses show the various organic compounds present in the leaching of CBs, such as nicotine, octanoic acid, trifluoroacetic acid, and 1,2,4trimethylcyclohexane which is considered a toxic compound; at the same time, carcinogenic substances such as dichloromethane, 2-ethylphenol, and pyridine were also found. These compounds were not detected in the leaching of activated carbons due to the pyrolysis and activation conditions used in their synthesis.

\subsection{Effect of Temperature, Type of Water, and Solution $\mathrm{pH}$ on Adsorption Equilibrium}

The efficiency of the adsorbent material for the removal of phenol was performed by obtaining the adsorption isotherms at 10,25 , and $40{ }^{\circ} \mathrm{C}$, keeping the solution $\mathrm{pH}$ at 7. Figure 5 a shows the adsorption isotherms at the three different temperatures, where an L-type behavior was observed, according to the Giles classification [32]. These results are in agreement with previous reports that the aromatic ring of phenol is adsorbed in parallel to the graphene layers of the carbon material [24,33]. It was also observed that phenol removal is gradually improved by decreasing the system temperature from 40 to $10^{\circ} \mathrm{C}$. For example, at an equilibrium concentration of $1200 \mathrm{mg} \mathrm{L}^{-1}$, the adsorption capacities were approximately 200,248 , and $272 \mathrm{mg} \mathrm{g}^{-1}$ at 40,25 , and $10^{\circ} \mathrm{C}$, respectively. 
These results indicate that a decrease in temperature from 40 to $25{ }^{\circ} \mathrm{C}$ and 40 to $10{ }^{\circ} \mathrm{C}$ improves the adsorption capacity of the material by $25 \%$ and $35 \%$, respectively, showing the exothermic nature of the adsorption process. It has been reported that the phenol adsorption process on activated carbon shows different trends, i.e., some authors have reported an endothermic process $[24,34]$, while other studies indicated that the adsorption process is exothermic $[33,35]$. This behavior could be related to the chemical nature of the surface material, since the number and the type of the surface functional groups present in the material can be influenced by the active carbon preparation conditions (chemical/physical treatment) and the precursor material [10].

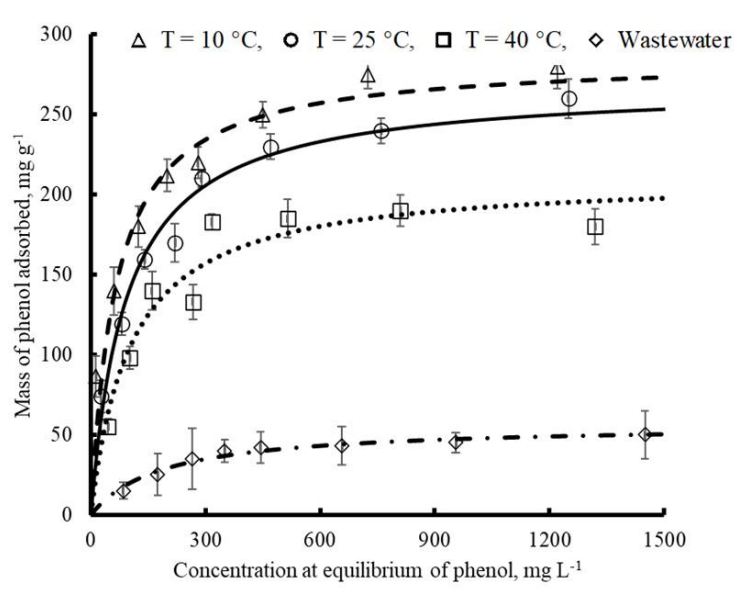

(a)

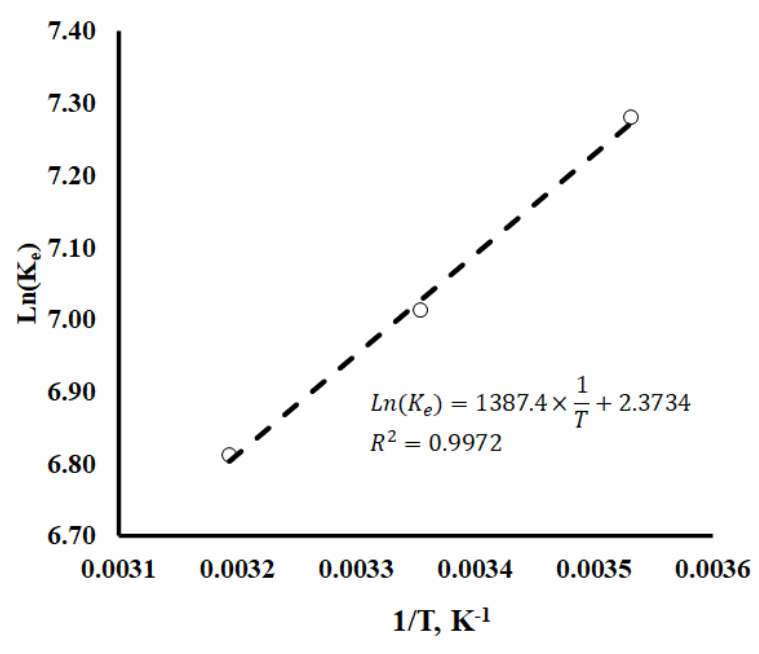

(b)

Figure 5. Adsorption isotherms of phenol on activated carbon as a function of temperature and type of water: (a) effect of the temperature and type of water; (b) Van 't Hoff plot.

The experimental data were fitted using the Langmuir isotherm model represented by the following equation:

$$
\mathrm{q}_{\mathrm{e}}=\frac{\mathrm{q}_{\mathrm{m}} \mathrm{KC}_{\mathrm{e}}}{1+\mathrm{KC}_{\mathrm{e}}}
$$

where $\mathrm{q}_{\mathrm{e}}$ represents the equilibrium adsorption capacity in $\mathrm{mg} \mathrm{g}^{-1}, \mathrm{C}_{\mathrm{e}}$ is the equilibrium concentration in $\mathrm{mg} \mathrm{L}^{-1}, \mathrm{q}_{\mathrm{m}}$ is the maximum adsorption capacity in $\mathrm{mg} \mathrm{g}^{-1}$, and $\mathrm{K}$ is the equilibrium constant in $\mathrm{L} \mathrm{mg}^{-1}$. The $\mathrm{q}_{\mathrm{m}}$ and $\mathrm{K}$ values were obtained by a nonlinear fit using Statistica 10.0 software, and their values are recorded in Table 4 together with the $R^{2}$ values.

Table 4. Langmuir isotherm fitting parameters of the phenol adsorption over activated carbon pellets.

\begin{tabular}{cccccc}
\hline Temperature $\left({ }^{\circ} \mathbf{C}\right)$ & Type of Water & $\mathbf{K}\left(\mathbf{L ~ m g} \mathbf{~ m}^{-\mathbf{1}}\right.$ & $\mathbf{K}_{\mathbf{e}}$ & $\mathbf{q}_{\mathbf{m}} \mathbf{( \mathbf { m g ~ g } ^ { - \mathbf { 1 } } )}$ & $\mathbf{R}^{\mathbf{2}}$ \\
\hline 10 & Deionized water & 0.01542 & 1451.17 & 285.11 & 0.9756 \\
25 & Deionized water & 0.01180 & 1110.49 & 268.9 & 0.9846 \\
40 & Deionized water & 0.00965 & 908.16 & 211.45 & 0.9563 \\
25 & Wastewater & 0.00530 & 498.78 & 56.58 & 0.9886 \\
\hline
\end{tabular}

Table 4 shows that the $\mathrm{qm}_{\mathrm{m}}$ values are in the range of $211.45-285.11 \mathrm{mg} \mathrm{g}^{-1}$ in the interval of temperatures studied. In addition, by the $\mathrm{R}^{2}$ values, it was concluded that the Langmuir model satisfactorily fitted the experimental data as shown in Figure 5a. Although there are other isotherm models in the literature with more fit parameters that would lead to obtaining $R^{2}$ values close to 1 , the Langmuir model was chosen because it physically interprets the phenomena, since the phenol molecule adsorbs in a monolayer on 
the surface of the carbonaceous material because of the average width of the micropore and the dimensions of the adsorbate molecule.

The changes in Gibbs free energy $\left(\Delta \mathrm{G}^{0}\right)$, enthalpy $\left(\Delta \mathrm{H}^{0}\right)$, and entropy $\left(\Delta \mathrm{S}^{0}\right)$ were estimated from the transformation of $\mathrm{K}$ values reported in Table 4 using the following equations [36]:

$$
\begin{gathered}
\operatorname{Ln}\left(\mathrm{K}_{\mathrm{e}}\right)=\frac{\Delta \mathrm{S}^{\circ}}{\mathrm{R}}-\frac{\Delta \mathrm{H}^{\circ}}{\mathrm{R}} \frac{1}{\mathrm{~T}} \\
\Delta \mathrm{G}^{\circ}=-\mathrm{RTLn}\left(\mathrm{K}_{\mathrm{e}}\right) \\
\mathrm{K}_{\mathrm{e}}=\frac{1000 \times \mathrm{Mw} \times[\text { phenol }]^{\circ} \times \mathrm{K}}{\gamma}
\end{gathered}
$$

where $\mathrm{Mw}$ is the molecular weight of phenol; [phenol] ${ }^{\circ}$ is the standard concentration of phenol $\left(1 \mathrm{~mol} \mathrm{~L}^{-1}\right)$; $\mathrm{R}$ is the universal gas constant in $\mathrm{kJ} \mathrm{mol}^{-1} \mathrm{~K}^{-1}$; $\mathrm{T}$ is the absolute temperature; and $\gamma$ is the coefficient of activity (dimensionless). It was assumed that the phenol solution is diluted to suppose that $\gamma=1$. The relationship between $\operatorname{Ln}\left(\mathrm{K}_{\mathrm{e}}\right) \mathrm{vs.} 1 / \mathrm{T}$ is known as the Van 't Hoff plot, and it is shown in Figure 5b along with the prediction of Equation (3), where it is evident that a linear behavior of the experimental values in the range of temperatures analyzed is found. From this plot, the values of $\Delta \mathrm{H}^{\circ}$ and $\Delta \mathrm{S}^{\circ}$ were $-11,387.4 \mathrm{~J} \mathrm{~mol}^{-1}$ and $\Delta \mathrm{S}^{\circ} 19.73 \mathrm{~J} \mathrm{~mol}^{-1} \mathrm{~K}^{-1}$, respectively. The $\Delta \mathrm{G}^{\circ}$ values were $-17,138.2$, $-17,382.86$, and $-17,773.73 \mathrm{~J} \mathrm{~mol}^{-1}$ at $283.15,298.15$, and $213.15 \mathrm{~K}$, respectively. These results corroborated the feasibility and the exothermic nature of the adsorption process. In addition, a positive $\Delta \mathrm{S}^{\circ}$ value indicates an increase in the level of disorder and randomness at the solid-solution interface during the phenol adsorption process.

Figure 5a also presents the phenol adsorption isotherm obtained with wastewater at $25^{\circ} \mathrm{C}$ and $\mathrm{pH}$ 7. The results indicate that the adsorption capacity of the activated carbon is drastically reduced with this type of water, reaching a maximum value of $56 \mathrm{mg} \mathrm{g}^{-1}$, showing an approximate reduction of $80 \%$ compared with the adsorption capacity obtained using ultrapure water. A physicochemical analysis of the water revealed a high presence of metal ions, which can block the pores of the adsorbent, preventing the diffusion of phenol towards the active sites. Similarly, the presence of organic matter contributes to a decrease in the adsorption capacity of activated carbons as reported in the literature [37]. Hence, the adsorption capacity of the material was reduced using wastewater. Figure 6 displays a micrograph of activated carbon exposed to wastewater. The micrograph shows a large number of crystals deposited on the surface of the adsorbent. Additionally, the EDS analysis confirmed the presence of some species such as $\mathrm{Al}, \mathrm{C}, \mathrm{Ca}, \mathrm{Cl}, \mathrm{Fe}, \mathrm{K}, \mathrm{Mg}, \mathrm{Na}, \mathrm{O}, \mathrm{P}$ $\mathrm{S}, \mathrm{Si}$, and Ti.

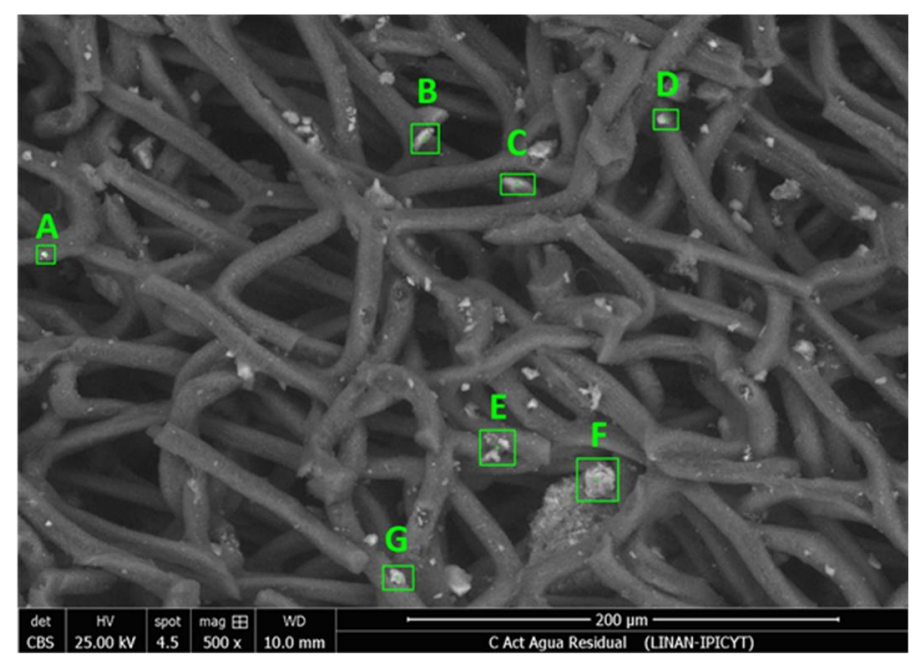

Figure 6. Micrographs obtained by SEM for activated carbon after adsorption with wastewater. 
The solution $\mathrm{pH}$ is one of the most relevant factors in the study of adsorption processes since it directly affects the surface charge of the material and the speciation of the solute. To evaluate this effect, the adsorption capacities were obtained at $\mathrm{pH} 2,5,7,10$, and 11 . The results are illustrated in Figure 7, where it can be observed that the adsorption capacity remained almost constant $\left(\mathrm{q} \approx 215 \mathrm{mg} \mathrm{g}^{-1}\right)$ in a pH range between 2 and 7 , but it decreased linearly when the $\mathrm{pH}$ increased from 7 to 11 . Thus, the adsorption capacity decreased by $43 \%$, thereby increasing the $\mathrm{pH}$ of the solution from 7 to 11 . These results are explained by considering that the activated carbon presented a $\mathrm{pH}_{\mathrm{PZC}}=9.02$, so that when the solution $\mathrm{pH}>\mathrm{pH}_{\mathrm{PZC}}$, the surface of the material is negatively charged. Thus, considering that the $\mathrm{pKa}$ value of phenol is 9.86, it can be assumed that at $\mathrm{pH}$ values higher than 9.86 , the phenol molecule is negatively charged. This generates an increase in the repulsive electrostatic interactions as the solution $\mathrm{pH}$ is augmented, causing a progressive decrease in the adsorption capacity. On the other hand, at $\mathrm{pH}$ values from 2 to 7 , the phenol molecule is neutral, indicating that in this $\mathrm{pH}$ range, the adsorption mechanism is governed by $\pi-\pi$ interactions.

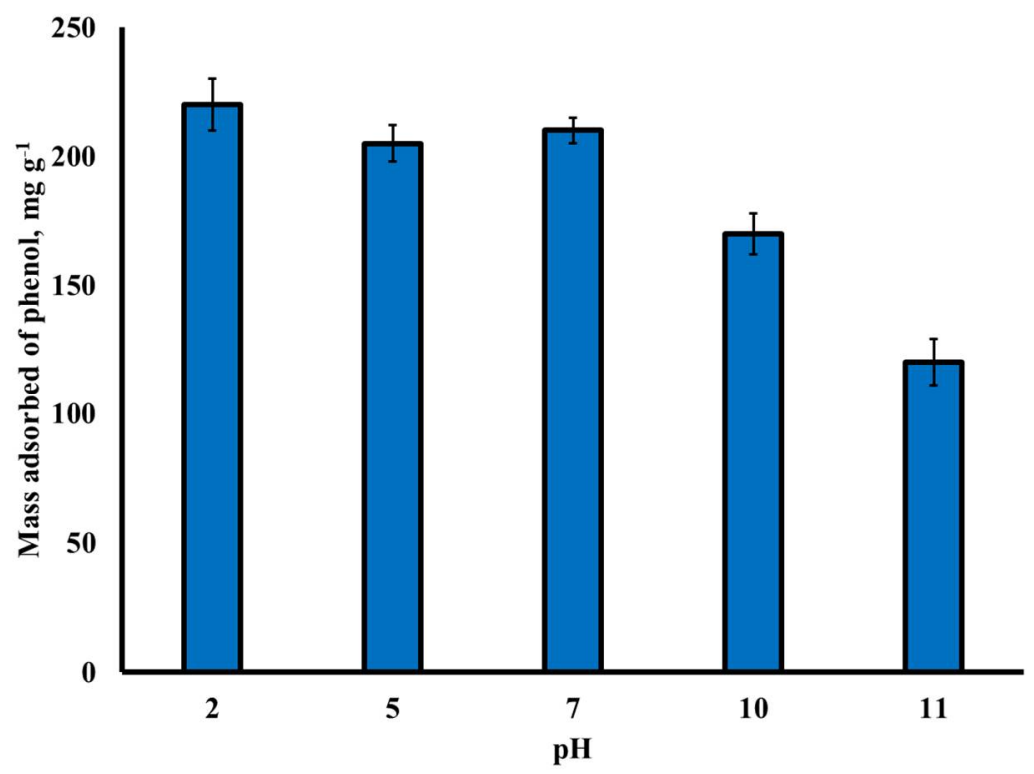

Figure 7. Effect of the solution $\mathrm{pH}$ on the adsorption capacity.

Table 5 shows maximal adsorption capacities obtained in previous research for phenol removal using activated carbon prepared from different agroindustrial waste. The activated carbon prepared in this study shows a high adsorption capacity compared to most of the other activated carbons obtained from agroindustrial waste. In this sense, the superficial functional groups and microporosity developed in the activated carbon obtained from CBs (under the preparation conditions used) are responsible for having a good material for removing organic low-sized molecules such as phenol. 
Table 5. Maximum adsorption capacities for phenol adsorption using activated carbon produced from different agroindustrial wastes.

\begin{tabular}{|c|c|c|c|}
\hline $\begin{array}{c}\text { Activated Carbon Obtained from Different } \\
\text { Raw Materials }\end{array}$ & $\mathrm{T}\left({ }^{\circ} \mathrm{C}\right)$ & $\mathrm{q}_{\max }\left(\mathrm{mg} \mathrm{g}^{-1}\right)$ & Ref. \\
\hline Black wattle bark waste & 25 & 85.75 & [24] \\
\hline Toona sinensis leaves & 25 & 325.0 & [35] \\
\hline Tithonia diversifolia & 25 & 50.55 & [34] \\
\hline $\begin{array}{c}\text { Rise husk-KOH } \\
\text { Rise husk-KOH/EDTA-4Na }\end{array}$ & 25 & $\begin{array}{l}194.2 \\
215.3\end{array}$ & [10] \\
\hline Coconut shell & 25 & 144.9 & [33] \\
\hline Avocado kernel seeds & 25 & 90.0 & {$[38]$} \\
\hline Cigarette filters & 25 & 268.9 & Present study \\
\hline
\end{tabular}

\subsection{Adsorption Rate}

The adsorption rate is a crucial parameter for scaling-up fixed-bed adsorbers since it directly influences their size. To investigate this aspect, decay curves were obtained at a different initial concentration (102.7-1520.1 $\mathrm{mg} \mathrm{L}^{-1}$ ), keeping the adsorbent mass and the solution volume constant. Consequently, each kinetic curve presented a different equilibrium adsorption capacity, $\mathrm{q}_{\mathrm{e}}$. The operating conditions for each adsorption kinetic are reported in Table 6, while the experimental data are presented in Figure 8a,b. In both figures, the time to reach equilibrium increased considerably with the rising of the adsorbed mass at equilibrium. For example, qe values of 73.79, 196.7, and $240 \mathrm{mg} \mathrm{g}^{-1}$ were obtained for the equilibrium times of 6000, 20,000, and 30,000 min, respectively. These results show an exponential increase in the equilibrium time as $\mathrm{q}_{\mathrm{e}}$ rises. Leyva-Ramos et al. [19] investigated the adsorption of phenol on activated carbon cloth (fibril diameter of $5 \mathrm{~mm}$, an average pore diameter of $1.95 \mathrm{~nm}$ ); they found that the time to achieve equilibrium was only $10 \mathrm{~min}$ [19], which is much less than that found in this present work. On the other hand, Lorenc-Grabowska et al. [18] used six microporous activated carbons to evaluate the phenol adsorption rate, and they found that the time to reach equilibrium was 1080, 1440, 1440, 2700, 3120, and $7200 \mathrm{~min}$ for the CS, CWZ, ASN, PFA, PET, and PAN samples, respectively [18]. It is essential to mention that the six samples showed a maximum pore size distribution between 1 and $1.4 \mathrm{~nm}$. From the results, it can be inferred that the adsorption rate of phenol in microporous materials depends drastically on the average width of the micropores. Therefore, the high equilibrium times obtained in this work are attributed to the narrow microporosity $(0.4-0.8 \mathrm{~nm})$ of the material, which causes the diffusion phenomena inside the pores. This performance becomes more evident as the number of adsorbed molecules increases, which induces partial blockage of the porous structure of the material, increasing the equilibrium time.

Table 6. Experimental conditions and mass transport parameters estimated by applying the diffusional model with $\varepsilon_{\mathrm{p}}=0.6, \rho_{\mathrm{p}}=1.1 \mathrm{~g} \mathrm{~cm}^{-3}$, and $\mathrm{R}_{\mathrm{p}}=6.5 \mu \mathrm{m}$.

\begin{tabular}{cccccc}
\hline Exp. Number & $\mathbf{C}_{\mathbf{A} \mathbf{0}} \mathbf{( \mathbf { m g ~ L } ^ { - 1 } )}$ & $\mathbf{q}_{\mathbf{e}} \mathbf{( \mathbf { m g ~ g } ^ { - \mathbf { 1 } } )}$ & $\mathbf{k}_{\mathbf{L}} \times \mathbf{1 0}^{\mathbf{5}} \mathbf{( \mathbf { c m ~ s } ^ { - \mathbf { 1 } } )}$ & $\left.\mathbf{D}_{\mathbf{e p}} \mathbf{( c m}^{\mathbf{2}} \mathbf{s}^{-\mathbf{1}}\right)$ & $\boldsymbol{\tau}$ \\
\hline 1 & 102.7 & 73.79 & 3.51 & $6.10 \times 10^{-10}$ & 7967 \\
2 & 201.3 & 119.1 & 3.85 & $1.55 \times 10^{-10}$ & 31,354 \\
3 & 310.2 & 169.4 & 3.76 & $9.10 \times 10^{-11}$ & 53,406 \\
4 & 405.2 & 196.7 & 4.23 & $8.35 \times 10^{-11}$ & 58,203 \\
5 & 500.5 & 210.3 & 3.57 & $4.02 \times 10^{-11}$ & 120,895 \\
6 & 726.3 & 181.2 & 5.56 & $8.11 \times 10^{-12}$ & 599,260 \\
7 & 1017.3 & 235 & 5.47 & $6.84 \times 10^{-12}$ & 710,526 \\
8 & 1520.1 & 240 & 5.66 & $5.50 \times 10^{-12}$ & 883,636 \\
\hline
\end{tabular}




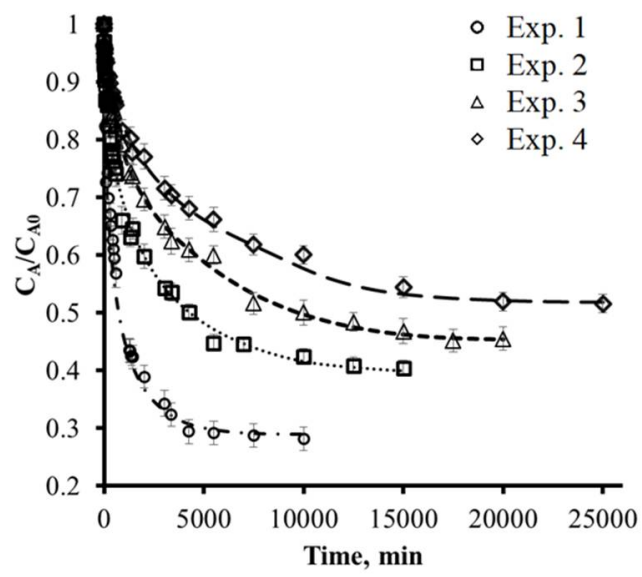

(a)

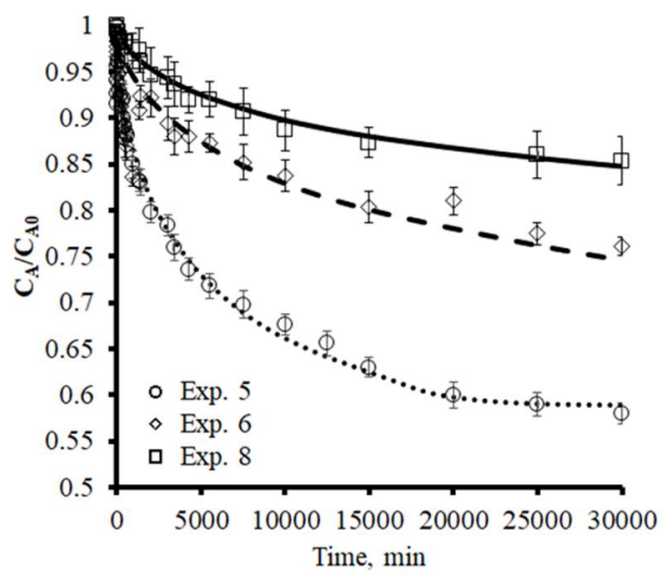

(b)

Figure 8. Concentration decay curves of phenol on activated carbon pellets for (a) Exp. 1-4 and (b) Exp. 5-8. The lines represent the prediction of the diffusional model.

In the literature, different mathematical models were reported to interpret the adsorption rate. These models are based on one or more mass transfer resistances involved during the process (external mass transfer, intraparticle diffusion, or adsorption at an active site). The most widely used mathematical models are kinetic models (first order and second order), which ignore both the external mass transfer as the intraparticle diffusion, and they only consider the adsorption on an active site. These models would adequately interpret the experimental data. However, their application would have no physical meaning since intraparticle diffusion plays an important role in this system. For this reason, the experimental data were interpreted using a diffusional model based on the pore volume diffusion. This model was developed in a previous work [19] and is given by the following set of equations.

$$
\begin{gathered}
\mathrm{V} \frac{\mathrm{d} \mathrm{C}_{\mathrm{A}}}{\mathrm{dt}}=-\mathrm{mSk}_{\mathrm{L}}\left(\mathrm{C}_{\mathrm{A}}-\left.\mathrm{C}_{\mathrm{Ar}}\right|_{\mathrm{r}=\mathrm{Rp}}\right) \\
\mathrm{t}=0 \mathrm{C}_{\mathrm{A}}=\mathrm{C}_{\mathrm{A} 0} \\
\varepsilon_{\mathrm{p}} \frac{\partial \mathrm{C}_{\mathrm{Ar}}}{\partial \mathrm{t}}+\rho_{\mathrm{p}} \frac{\partial \mathrm{q}}{\partial \mathrm{t}}=\frac{1}{\mathrm{r}} \frac{\partial}{\partial \mathrm{r}}\left[\mathrm{r}\left(\mathrm{D}_{\mathrm{ep}} \frac{\partial \mathrm{C}_{\mathrm{Ar}}}{\partial \mathrm{r}}\right)\right] \\
\mathrm{C}_{\mathrm{Ar}}=0 \quad \mathrm{t}=0 \quad 0 \leq \mathrm{r} \leq \mathrm{R}_{\mathrm{p}} \\
\left.\frac{\partial \mathrm{C}_{\mathrm{Ar}}}{\partial \mathrm{r}}\right|_{\mathrm{r}=0}=0 \\
\left.\mathrm{D}_{\mathrm{ep}} \frac{\partial \mathrm{C}_{\mathrm{Ar}}}{\partial \mathrm{r}}\right|_{\mathrm{r}=\mathrm{Rp}}=\mathrm{k}_{\mathrm{L}}\left(\mathrm{C}_{\mathrm{A}}-\left.\mathrm{C}_{\mathrm{Ar}}\right|_{\mathrm{r}=\mathrm{R}}\right)
\end{gathered}
$$

where $\mathrm{V}$ is volume of the solution in $\mathrm{L} ; \mathrm{S}$ is the external surface area per mass of adsorbent in $\mathrm{cm}^{2} \mathrm{~g}^{-1} ; \mathrm{C}_{\mathrm{Ar}}$ is the concentration of phenol within the particle at distance $\mathrm{r}$ in $\mathrm{mg} \mathrm{L}^{-1}$; $C_{\text {Ar|Rp }}$ is the concentration of phenol at the external surface of the particle at $r=R_{p}$ in $\mathrm{mg} \mathrm{L}^{-1} ; \mathrm{k}_{\mathrm{L}}$ is the external mass transfer coefficient in liquid phase in $\mathrm{cm} \mathrm{s}^{-1}$; $\mathrm{D}_{\text {ep }}$ is the effective pore volume diffusion coefficient in $\mathrm{cm}^{2} \mathrm{~s}^{-1} ; \varepsilon_{\mathrm{p}}$ is the void fraction of adsorbent particles; $\rho_{\mathrm{p}}$ is the density of adsorbent particles in $\mathrm{g} \mathrm{cm}^{-3} ; \mathrm{R}_{\mathrm{p}}$ is the radio of the fiber in $\mathrm{cm}$; and $\mathrm{q}$ is the mass of phenol adsorbed in $\mathrm{mg} \mathrm{g}^{-1}$. Equations (6) and (8) represent the mass balance in the solution and inside the particle, while the initial conditions are given by Equations (7) and (9). Equation (10) is a boundary condition that represents the absence of mass flux at the center of the particle, whereas Equation (11) establishes the continuity of fluxes at the external surface of the particle. Finally, if the adsorption rate of phenol on 
an active site is instantaneous, it is appropriate to consider a local equilibrium to be taking place between the phenol concentration in the solution inside the pore and the mass of phenol adsorbed on the pore surface. This equilibrium is given by Equation (2), which is the mathematical relationship between $\mathrm{q}$ and $\mathrm{C}_{\mathrm{Ar}}$.

To solve the mathematical model denoted by Equations (6)-(11), it is necessary to know the values of $k_{L}$ and $D_{e p}$. The $k_{L}$ value was assessed by the procedure suggested by Furusawa and Smith [39]. This method is based on the fact that when $t=0$ min, then $\mathrm{C}_{\mathrm{Ar}}=0 \mathrm{mg} \mathrm{L}^{-1}$ and $\mathrm{C}_{\mathrm{A}} \rightarrow \mathrm{C}_{\mathrm{A} 0}$. Substituting these conditions in Equation (6), the following equation can be obtained:

$$
\mathrm{k}_{\mathrm{L}}=-\frac{\mathrm{V}}{\mathrm{mS}}\left(\frac{\mathrm{dC}_{\mathrm{A}}}{\mathrm{dt}}\right)_{\mathrm{t} \rightarrow 0}
$$

The term at the left of Equation (12) is the slope of the concentration decay curve estimated by using the first two data points at $t=0$ and $t=5 \mathrm{~min}$. The values of $\mathrm{k}_{\mathrm{L}}$ are summarized in Table 6 and are ranged from $3.51 \times 10^{-5}$ to $5.66 \times 10^{-5} \mathrm{~cm} \mathrm{~s}^{-1}$, which are lower than those reported in the literature for the adsorption of aromatic compounds on carbon materials [40-42]. This difference is mainly attributed to the long times required to achieve equilibrium in this system.

The optimal $D_{\text {ep }}$ value for each experiment was obtained by fitting the numerical solution of the diffusional model to the experimental data, minimizing the following objective function:

$$
\text { Error }=\int_{t=0}^{t \text { final }}\left(C_{A, \exp }-C_{A, P r e d}\right)^{2} d t
$$

where $C_{A \text {,exp }}$ is the experimental concentration of phenol in $\mathrm{mg} \mathrm{L}^{-1}$ and $C_{A, P r e d}$ is the concentration of phenol predicted with the diffusional model in $\mathrm{mg} \mathrm{L}^{-1}$.

As an example, Figure 9 shows the experimental data for Exp. 1 with the prediction of the diffusional model using different values of $D_{e p}$. This figure indicates that the prediction of the model is highly influenced by the value of $\mathrm{D}_{\mathrm{ep}}$. For instance, for values of $D_{\text {ep }}=4.86 \times 10^{-7} \mathrm{~cm}^{2} \mathrm{~s}$, the model predicts an adsorption rate almost ten times faster than those obtained experimentally, indicating that smaller values of $D_{e p} \lambda$ are necessary for improving the prediction of the experimental data. After performing an optimization process, the best value of $D_{e p}$ that matched the experimental data was $D_{e p}=6.10 \times 10^{-10} \mathrm{~cm}^{2} \mathrm{~s}^{-1}$, whose prediction (solid line) is illustrated in Figure 9.

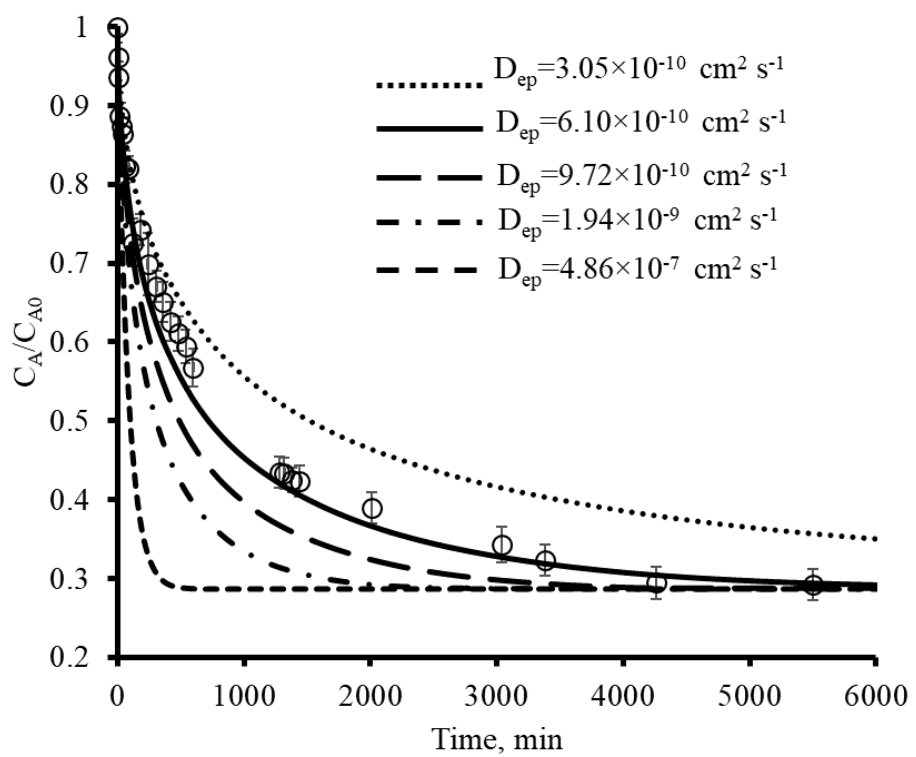

Figure 9. Concentration decay curve during the adsorption of phenol on activated carbon. The lines represent the prediction of diffusional model with different values of $\mathrm{D}_{\mathrm{ep}}$. 
A similar procedure was used to interpret the data for Exp. 2-8 from Table 6. The best fit of the experimental data is illustrated in Figure $8 a, b$, while the optimal $D_{e p}$ values are summarized in Table 6. From both figures, it can be inferred that the model adequately predicts the experimental data for all experimental conditions. Furthermore, it is observed in Table 6 that the $\mathrm{D}_{\mathrm{ep}}$ values decreased exponentially from $6.10 \times 10^{-10}$ to $5.50 \times 10^{-12} \mathrm{~cm}^{2} \mathrm{~s}^{-1}$ as the adsorbed mass at equilibrium increased from 73.79 to $240 \mathrm{mg} \mathrm{g}^{-1}$. From the optimized values of $D_{\text {ep }}$, the material's tortuosity factor, $\tau$, can be estimated using the following equation [43]:

$$
\tau=-\frac{\mathrm{D}_{\mathrm{AB}} \varepsilon_{\mathrm{p}}}{\mathrm{D}_{\mathrm{ep}}}
$$

The estimated values of $\tau$ are also collected in Table 6 , and they present a contrary trend to $D_{e p}$, that is, the value of $\tau$ increased exponentially with the rising of $q_{e}$. Tortuosity is defined as the relationship between the effective distance traveled by a species that moves by molecular diffusion per unit length of the medium [44]. For activated carbon, it was estimated that the value of $\tau$ varies between 2 and 6 due to its macro, meso, and microporous structure. Therefore, as the obtained activated carbon has micropores exclusively, it would be expected to obtain a $\tau$ value of less than 3 . However, the calculated $\tau$ values are above the values previously reported for activated carbons [43-45]. In addition, the value of $\tau$ is an intrinsic property of the material, and therefore its value must remain constant with different operating conditions. Thus, the values of $\tau$ calculated with Equation (14) have no physical meaning. A possible explanation for this behavior could be that the diffusion of phenol drastically decreases inside the pores of the material, because of its molecular size. Since it is quite similar to the size of the micropores, it can lead to hindered diffusion on the material. Saterfield et al. [46] modified Equation (14) to consider the effects of restrictive diffusion and in turn proposed the following equation:

$$
\mathrm{D}_{\mathrm{ep}}=\frac{\mathrm{D}_{\mathrm{AB}} \varepsilon_{\mathrm{p}} \mathrm{K}_{\mathrm{p}} \mathrm{K}_{\mathrm{r}}}{\tau}
$$

where $K_{p}$ and $K_{r}$ are the restriction factors for exclusion and friction, respectively. Several correlations have been developed to estimate $K_{p}$ and $K_{r}$, based on the relationship of the molecule size $\left(\mathrm{d}_{\mathrm{m}}\right)$, and the pore diameter $\left(\mathrm{L}_{0}\right)$, under the consideration that the pores are cylindrical and that the molecules are rigid spheres. The most common mathematical expressions are the Renkin equation (Equation (16)) and the Bungay-Brenner equation (Equation (17)) [47,48] described as:

$$
\begin{gathered}
K_{p}=(1-\zeta)^{2} \quad K_{r}=\frac{6 \pi}{K_{t}} \\
K_{t}=\frac{9 \pi^{2} \sqrt{2}}{4}(1-\zeta)^{-5 / 2}\left[1+\sum_{n=1}^{2} a_{n}(1-\zeta)^{n}\right]+\sum_{n=0}^{4}\left(a_{n+3}\right) \zeta^{n}
\end{gathered}
$$

where $\mathrm{a}_{1}=-73 / 60 ; \mathrm{a}_{2}=77,293 / 50,400 ; \mathrm{a}_{3}=-22.5083 ; \mathrm{a}_{4}=-5.6117 ; \mathrm{a}_{5}=-0.3363 ;$ $\mathrm{a}_{6}=-1.216 ; \mathrm{a}_{7}=1.64 ;$ and $\zeta$ represents the relationship between the phenol molecular size and the average width of the micropores. In this system, the value of $\zeta$ varies between $0.694(0.43 / 0.62)$ and $0.919(0.57 / 0.62)$, depending on the characteristic length of the phenol molecule (see Table 1). Substituting these values of $\zeta$ in Equations (16) and (17), $\mathrm{K}_{\mathrm{p}}$ and $\mathrm{K}_{\mathrm{r}}$ values are obtained, i.e., $4 \times 10^{-3}$ and $7.92 \times 10^{-6}$ for $\zeta=0.694$ and $\zeta=0.919$, correspondingly. These values indicate that the phenol adsorption rate is reduced between 248 and 125,000 folds due to the presence of restrictive phenomena. Therefore, this explains the high equilibrium time and consequently the low $\mathrm{D}_{\mathrm{ep}}$ values obtained. 
Saterfield et al. [46] also modified Equation (15) to include an additional parameter to take into account the obstruction effects due to adsorbed molecules on the surface of the adsorbent, in turn obtaining the following equation:

$$
\mathrm{D}_{\mathrm{ep}}=\frac{\mathrm{D}_{\mathrm{AB}} \varepsilon_{\mathrm{p}} \mathrm{K}_{\mathrm{p}} \mathrm{K}_{\mathrm{r}} \mathrm{K}_{\mathrm{a}}}{\tau}
$$

where $K_{a}$ is the correction factor for the restrictive effects caused by the adsorbed molecules. Leyva-Ramos et al. [48] proposed that Equation (18) can be expressed as follows:

$$
\frac{\mathrm{D}_{\mathrm{ep}}}{\mathrm{D}_{\mathrm{AB}} \varepsilon_{\mathrm{p}} \mathrm{K}_{\mathrm{p}} \mathrm{K}_{\mathrm{r}}}=\frac{\mathrm{K}_{\mathrm{a}}}{\tau}=\mathrm{D}_{\text {corr }}
$$

where $\mathrm{D}_{\text {corr }}$ is a dimensionless diffusion coefficient that incorporates the constraint corrections. An important feature of Equation (19) is that at the limit when $\mathrm{q}_{\mathrm{e}} \rightarrow 0$ and $\mathrm{K}_{\mathrm{a}} \rightarrow 1$, then $1 / D_{\text {corr }} \rightarrow \tau$.

The $1 / D_{\text {corr }}$ values were calculated using Equation (19), and the obtained values are presented in Figure 10a,b for the two representative phenol lengths. Additionally, the experimental data were correlated using the next correlation [48]:

$$
\frac{1}{D_{\text {corr }}}=\tau e^{a \times q_{e}}
$$

where a is a positive constant $\left(\mathrm{g} \mathrm{mg}^{-1}\right)$. This equation also meets the requirement that $1 / D_{\text {corr }} \rightarrow \tau$ as $q_{e} \rightarrow 0$. The values of $\tau$ were obtained by a nonlinear estimation, using the Statistica software being $\tau=3.3$ and $\tau=0.081$ for the phenol characteristic lengths of 0.43 and $0.57 \mathrm{~nm}$, respectively (see Figure 10a,b). It is evident that the second value of $\tau$ lacks physical meaning since for the straight and uniform pores, $\tau=1$. Therefore, the maximum value of $\tau$ for the carbon sample used in this work is the lower limit of reported values for activated carbons.

a

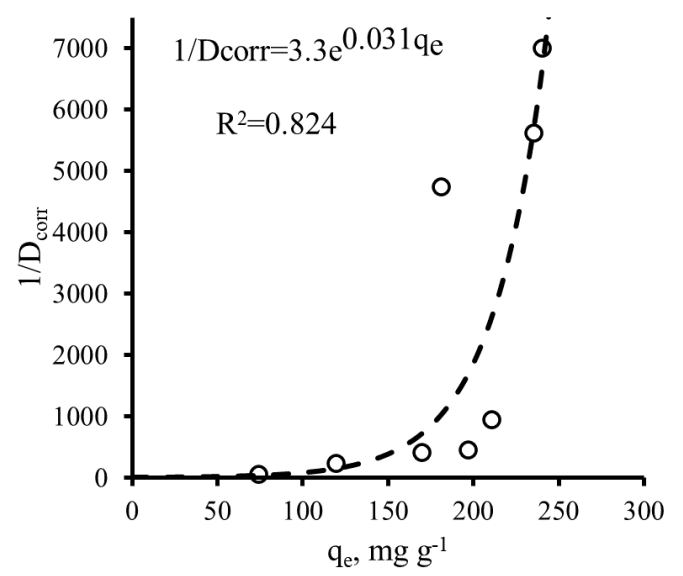

b

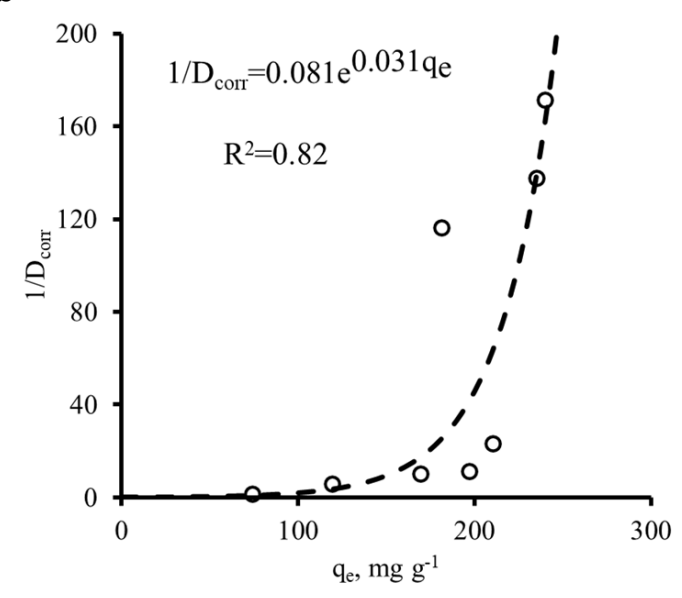

Figure 10. Effect of the adsorbed mass at equilibrium on the dimensionless effective diffusion coefficient.

\section{Conclusions}

In this work, activated carbon pellets were obtained from CBs, with an excellent specific area and wide applications as an adsorbent. This material was successfully used as an adsorbent material for phenol concentration $\left(\mathrm{q}_{\max }=268.9 \mathrm{mg} \mathrm{g}^{-1}\right)$.

Adsorption isotherms indicated that the aromatic ring of phenol is adsorbed parallel to the graphitic layer of activated carbon. In addition, the adsorption capacity improved by a decrease in temperature, showing the exothermic nature of the adsorption process. Phenol adsorption was favored at $\mathrm{pH}$ values from 2 to 7 since basic $\mathrm{pH}$ values led to an 
important decrease of adsorption capacities due to the repulsive electrostatic interactions between phenol and the negatively charged surface of the activated carbon.

The microporosity of the material is a crucial parameter; therefore, high equilibrium times were required, and activated carbon must be useful for adsorption of low-sized molecules (less than $8 \mathrm{~nm}$ ) to promote diffusion into the narrow micropores. It can thus be seen that intraparticle diffusion plays an important role in this system. Experimental data were fitted to a pore volume diffusion model that adequately predicted the experimental data to all conditions used. Finally, it was found that the tortuosity values obtained from this model for the activated carbon were $\tau=3.3$.

\section{Perspectives}

The obtention of an adsorbent material from cigarette waste makes it necessary to think about its adequate separation from the total municipal waste. Hence, its treatment implies taking action from its generation, e.g., the implementation of recollection points in many local places such as parks, restaurants, supermarkets, coffee shops, universities, among others. Currently, there are social organizations or movements in several cities around the world that are taking the initiative to collect this type of waste. Finding a use for this waste allows for the minimization of its negative impact on the environment and gives added value to this waste material. Therefore, the use of cigarette butts as a precursor of an adsorbent material can be a feasible and justified business option in the future.

Supplementary Materials: The following are available online at https://www.mdpi.com/article/10 .3390/pr9060934/s1, Figure S1: Thermogravimetric (TGA) analysis of CBs, Figure S2: Differential scanning calorimetry (DSC) analysis of CBs, Figure S3: FTIR spectra of CBs and activated carbon, [S1: Physicochemical characteristics of the wastewater exiting a treatment plant located in San Luis Potosi, Mexico].

Author Contributions: Conceptualization, N.A.M.-C. and R.O.-P.; methodology, A.F. and G.J.L.-D.; validation, A.I.Z.-G. and S.A.C.-B.; formal analysis, A.I.Z.-G.; investigation, R.O.-P.; writing—original draft preparation, A.I.Z.-G. and A.F.; writing-review and editing, R.O.-P. and R.F.-R. All authors have read and agreed to the published version of the manuscript.

Funding: This research received no external funding.

Institutional Review Board Statement: Not applicable.

Informed Consent Statement: Not applicable.

Data Availability Statement: The data presented in this study are available on request from the corresponding author.

Acknowledgments: Ana I. Zárate-Guzmán thanks Consejo Nacional de Ciencia y Tecnología (National Council of Science and Technology), CONACYT, Mexico, for the support received through "Convocatoria 2020: estancias posdoctorales por México". We would like to thank LINAN, IPICYT for providing laboratory support.

Conflicts of Interest: The authors declare no conflict of interest.

\section{References}

1. Marinello, S.; Lolli, F.; Gamberini, R.; Rimini, B. A second life for cigarette butts? A review of recycling solutions. J. Hazard. Mater. 2020, 384, 121245. [CrossRef] [PubMed]

2. Kurmus, H.; Mohajerani, A. The toxicity and valorization options of cigarette butts. Waste Manag. 2020, 104, 104-118. [CrossRef] [PubMed]

3. Araújo, M.C.B.; Costa, M.F. A critical review of the issue of cigarette butt pollution in coastal environments. Environ. Res. 2019, 172, 137-149. [CrossRef]

4. Alhokbany, N.S.; Naushad, M.; Kumar, V.; Al hatim, S.; Alshehri, S.M.; Ahamad, T. Self-nitrogen doped carbons aerogel derived from waste cigarette butts (cellulose acetate) for the adsorption of BPA: Kinetics and adsorption mechanisms. J. King Saud Univ. Sci. 2020, 32, 3351-3358. [CrossRef]

5. Abu-Danso, E.; Bagheri, A.; Bhatnagar, A. Facile functionalization of cellulose from discarded cigarette butts for the removal of diclofenac from water. Carbohydr. Polym. 2019, 219, 46-55. [CrossRef] 
6. Aldieri, L.; Ioppolo, G.; Vinci, C.P.; Yigitcanlar, T. Waste recycling patents and environmental innovations: An economic analysis of policy instruments in the USA, Japan and Europe. Waste Manag. 2019, 95, 612-619. [CrossRef]

7. Conradi, E.; Gonçalves, A.C.; Schwantes, D.; Manfrin, J.; Schiller, A.; Zimmerman, J.; Klassen, G.J.; Ziemer, G.L. Development of renewable adsorbent from cigarettes for lead removal from water. J. Environ. Chem. Eng. 2019, 7. [CrossRef]

8. Lima, H.H.C.; Maniezzo, R.S.; Kupfer, V.L.; Guilherme, M.R.; Moises, M.P.; Arroyo, P.A.; Rinaldi, A.W. Hydrochars based on cigarette butts as a recycled material for the adsorption of pollutants. J. Environ. Chem. Eng. 2018, 6, 7054-7061. [CrossRef]

9. Manfrin, J.; Gonçalves, A.C., Jr.; Schwantes, D.; Conradi, E., Jr.; Zimmermann, J.; Ziemer, G.L. Development of biochar and activated carbon from cigarettes wastes and their applications in Pb2+ adsorption. J. Environ. Chem. Eng. 2021, 9, 104980. [CrossRef]

10. Lv, S.; Li, C.; Mi, J.; Meng, H. A functional activated carbon for efficient adsorption of phenol derived from pyrolysis of rice husk, $\mathrm{KOH}$-activation and EDTA-4Na-modification. Appl. Surf. Sci. 2020, 510, 145425. [CrossRef]

11. Alves, D.C.S.; Coseglio, B.B.; Pinto, L.A.A.; Cadaval, T.R.S. Development of Spirulina/chitosan foam adsorbent for phenol adsorption. J. Mol. Liq. 2020, 309, 113256. [CrossRef]

12. Koochaki, C.B.; Khajavi, R.; Rashidi, A.; Mansouri, N.; Yazdanshenas, M.E. The effect of pre-swelling on the characteristics of obtained activated carbon from cigarette butts fibers. Biomass Convers. Biorefinery 2020, 10, 227-236. [CrossRef]

13. Bardestani, R.; Patience, G.S.; Kaliaguine, S. Experimental methods in chemical engineering: Specific surface area and pore size distribution measurements-BET, BJH, and DFT. Can. J. Chem. Eng. 2019, 97, 2781-2791. [CrossRef]

14. Bachmann, H.J.; Bucheli, T.D.; Dieguez-Alonso, A.; Fabbri, D.; Knicker, H.; Schmidt, H.P.; Ulbricht, A.; Becker, R.; Buscaroli, A.; Buerge, D.; et al. Toward the standardization of biochar analysis: The COST action TD1107 interlaboratory comparison. J. Agric. Food Chem. 2016, 64, 513-527. [CrossRef]

15. Moreno-Castilla, C.; Rivera-Utrilla, J.; Carrasco-Marín, F.; López-Ramón, M.V. On the carbon dioxide and benzene adsorption on activated carbons to study their micropore structure. Langmuir 1997, 13, 5208-5209. [CrossRef]

16. Landers, J.; Gor, G.Y.; Neimark, A.V. Density functional theory methods for characterization of porous materials. Colloids Surf. A Physicochem. Eng. Asp. 2013, 437, 3-32. [CrossRef]

17. Boehm, H.P. Some aspects of the surface chemistry of carbon blacks and other carbons. Carbon N. Y. 1994, 32, 759-769. [CrossRef]

18. Lorenc-grabowska, E. Effect of micropore size distribution on phenol adsorption on steam activated carbons. Adsorption 2016, 22, 599-607. [CrossRef]

19. Leyva-Ramos, R.; Ocampo-Perez, R.; Mendoza-Barron, J. External mass transfer and hindered diffusion of organic compounds in the adsorption on activated carbon cloth. Chem. Eng. J. 2012, 183, 141-151. [CrossRef]

20. Ocampo-Perez, R.; Leyva-Ramos, R.; Alonso-Davila, P.; Rivera-Utrilla, J.; Sanchez-Polo, M. Modeling adsorption rate of pyridine onto granular activated carbon. Chem. Eng. J. 2010, 165, 133-141. [CrossRef]

21. Masoudi Soltani, S.; Yazdi, S.K.; Hosseini, S. Effects of pyrolysis conditions on the porous structure construction of mesoporous charred carbon from used cigarette filters. Appl. Nanosci. 2014, 4, 551-569. [CrossRef]

22. Lowell, S.; Shields, J.E.; Thomas, M.A.; Thommes, M. Adsorption isotherms. In Characterization of Porous Solids and Powders: Surface Area, Pore Size and Density; Particle Technology Series; Springer: Dordrecht, The Netherlands, 2004.

23. Miao, Q.; Tang, Y.; Xu, J.; Liu, X.; Xiao, L.; Chen, Q. Activated carbon prepared from soybean straw for phenol adsorption. J. Taiwan Inst. Chem. Eng. 2013, 44, 458-465. [CrossRef]

24. Lütke, S.F.; Igansi, A.V.; Pegoraro, L.; Dotto, G.L.; Pinto, L.A.A.; Cadaval, T.R.S. Preparation of activated carbon from black wattle bark waste and its application for phenol adsorption. J. Environ. Chem. Eng. 2019, 7, 103396. [CrossRef]

25. Romero-Cano, L.A.; García-Rosero, H.; Gonzalez-Gutierrez, L.V.; Baldenegro-Pérez, L.A.; Carrasco-Marín, F. Functionalized adsorbents prepared from fruit peels: Equilibrium, kinetic and thermodynamic studies for copper adsorption in aqueous solution. J. Clean. Prod. 2017, 162, 195-204. [CrossRef]

26. Katepalli, H.; Bikshapathi, M.; Sharma, C.S.; Verma, N.; Sharma, A. Synthesis of hierarchical fabrics by electrospinning of PAN nanofibers on activated carbon microfibers for environmental remediation applications. Chem. Eng. J. 2011, 171, 1194-1200. [CrossRef]

27. Li, C.; Ma, H.; Venkateswaran, S.; Hsiao, B.S. Highly efficient and sustainable carboxylated cellulose filters for removal of cationic dyes / heavy metals ions. Chem. Eng. J. 2020, 389, 123458. [CrossRef]

28. El-Hendawy, A.N.A. Variation in the FTIR spectra of a biomass under impregnation, carbonization and oxidation conditions. J. Anal. Appl. Pyrolysis 2006, 75, 159-166. [CrossRef]

29. Pretsch, E.; Badertscher, M.; Buhlmann, P. Structure Determination of Organic Compounds, 4th ed.; Springer: Berlin/Heidelberg, Germany, 2009; ISBN 9783540938095.

30. Secretaria de Salud NOM-127-SSA1-1994; 1994; pp. 73-79. Available online: http://www.salud.gob.mx/unidades/cdi/nom/12 7ssa14.html (accessed on 15 April 2021).

31. World Health Organization (WHO). Guidelines for Drinking-Water Quality, 4th ed.; 2017; ISBN 9789241549950. Available online: https:/ / www.who.int/publications/i/item/9789241549950 (accessed on 15 April 2021).

32. Giles, C.H.; Smith, D.; Huitson, A. A general treatment and classification of the solute adsorption isotherm. I. Theoretical. J. Colloid Interface Sci. 1974, 47, 755-765. [CrossRef]

33. Zhang, D.; Huo, P.; Liu, W. Behavior of phenol adsorption on thermal modified activated carbon. Chin. J. Chem. Eng. 2016, 24, 446-452. [CrossRef] 
34. Supong, A.; Bhomick, P.C.; Karmaker, R.; Ezung, S.L.; Jamir, L.; Sinha, U.B.; Sinha, D. Experimental and theoretical insight into the adsorption of phenol and 2,4-dinitrophenol onto Tithonia diversifolia activated carbon. Appl. Surf. Sci. 2020, 529, 147046. [CrossRef]

35. Kong, X.; Gao, H.; Song, X.; Deng, Y.; Zhang, Y. Adsorption of phenol on porous carbon from Toona sinensis leaves and its mechanism. Chem. Phys. Lett. 2020, 739, 137046. [CrossRef]

36. Lima, E.C.; Hosseini-Bandegharaei, A.; Moreno-Piraján, J.C.; Anastopoulos, I. A critical review of the estimation of the thermodynamic parameters on adsorption equilibria. Wrong use of equilibrium constant in the Van't Hoof equation for calculation of thermodynamic parameters of adsorption. J. Mol. Liq. 2019, 273, 425-434. [CrossRef]

37. Summers, R.S.; Haist, B.; Koehler, J.; Ritz, J.; Zimmer, G.; Sontheimer, H. The influence of background organic matter on GAC adsorption. J. Am. Water Work. Assoc. 1989, 81, 66-74. [CrossRef]

38. Rodrigues, L.A.; da Silva, M.L.C.P.; Alvarez-Mendes, M.O.; dos Reis Coutinho, A.; Thim, G.P. Phenol removal from aqueous solution by activated carbon produced from avocado kernel seeds. Chem. Eng. J. 2011, 174, 49-57. [CrossRef]

39. Furusawa, T.; Smith, J.M. Fluid-Particle and intraparticle mass transport rates in slurries. Ind. Eng. Chem. Fundam. 1973, 12, 197-203. [CrossRef]

40. Moreno-Pérez, J.; Pauletto, P.S.; Cunha, A.M.; Bonilla-Petriciolet, Á.; Salau, N.P.G.; Dotto, G.L. Three-dimensional mass transport modeling of pharmaceuticals adsorption inside $\mathrm{ZnAl} /$ biochar composite. Colloids Surf. A Physicochem. Eng. Asp. $2021,614$. [CrossRef]

41. Pauletto, P.S.; Moreno-Pérez, J.; Hernández-Hernández, L.E.; Bonilla-Petriciolet, A.; Dotto, G.L.; Salau, N.P.G. Novel biochar and hydrochar for the adsorption of 2-nitrophenol from aqueous solutions: An approach using the PVSDM model. Chemosphere 2021, 269. [CrossRef] [PubMed]

42. Flores-Cano, J.V.; Sánchez-Polo, M.; Messoud, J.; Velo-Gala, I.; Ocampo-Pérez, R.; Rivera-Utrilla, J. Overall adsorption rate of metronidazole, dimetridazole and diatrizoate on activated carbons prepared from coffee residues and almond shells. J. Environ. Manage. 2016, 169, 116-125. [CrossRef]

43. Leyva-Ramos, R.; Geankoplis, C.J. Diffusion in liquid-filled pores of activated carbon. I. Pore volume diffusion. Can. J. Chem. Eng. 1994, 72, 262-271. [CrossRef]

44. Piai, L.; Dykstra, J.E.; Adishakti, M.G.; Blokland, M.; Langenhoff, A.A.M.; van der Wal, A. Diffusion of hydrophilic organic micropollutants in granular activated carbon with different pore sizes. Water Res. 2019, 162, 518-527. [CrossRef]

45. Luna, F.M.T.; Oliveira Filho, A.N.; Araújo, C.C.B.; Azevedo, D.C.S.; Cavalcante, C.L. Adsorption of polycyclic aromatic hydrocarbons from heavy naphthenic oil using commercial activated carbons. 1. Fluid-Particle studies. Ind. Eng. Chem. Res. 2016, 55, 8176-8183. [CrossRef]

46. Satterfield, C.N.; Colton, C.K.; Pitcher, W.H. Restricted diffusion in liquids within fine pores. AIChE J. 1973, 19, 628-635. [CrossRef]

47. Bungay, P.M.; Brenner, H. The motion of a closely-fitting sphere in a fluid-filled tube. Int. J. Multiph. Flow 1973, 1, 25-56. [CrossRef]

48. Leyva-Ramos, R.; Diaz-Flores, P.E.; Leyva-Ramos, J.; Femat-Flores, R.A. Kinetic modeling of pentachlorophenol adsorption from aqueous solution on activated carbon fibers. Carbon N. Y. 2007, 45, 2280-2289. [CrossRef] 